\title{
Stable carbon isotope ratios of ambient aromatic volatile organic compounds
}

\author{
Anna Kornilova ${ }^{1}$, Lin Huang ${ }^{2}$, Marina Saccon ${ }^{1}$, and Jochen Rudolph ${ }^{1}$ \\ ${ }^{1}$ Centre for Atmospheric Chemistry, York University, Toronto, ON, M3J 1P3, Canada \\ ${ }^{2}$ Environment Canada, Toronto, ON, M3H 5T4, Canada \\ Correspondence to: Jochen Rudolph (rudolphj@yorku.ca)
}

Received: 25 May 2016 - Published in Atmos. Chem. Phys. Discuss.: 2 June 2016

Revised: 24 August 2016 - Accepted: 26 August 2016 - Published: 21 September 2016

\begin{abstract}
Measurements of mixing ratios and stable carbon isotope ratios of aromatic volatile organic compounds (VOC) in the atmosphere were made in Toronto (Canada) in 2009 and 2010. Consistent with the kinetic isotope effect for reactions of aromatic VOC with the $\mathrm{OH}$ radical the observed stable carbon isotope ratios are on average significantly heavier than the isotope ratios of their emissions. The change of carbon isotope ratio between emission and observation is used to determine the extent of photochemical processing (photochemical age, $\int[\mathrm{OH}] \mathrm{d} t$ ) of the different VOC. It is found that $\int[\mathrm{OH}] \mathrm{d} t$ of different VOC depends strongly on the VOC reactivity. This demonstrates that for this set of observations the assumption of a uniform $\int[\mathrm{OH}] \mathrm{d} t$ for VOC with different reactivity is not justified and that the observed values for $\int[\mathrm{OH}] \mathrm{d} t$ are the result of mixing of VOC from air masses with different values for $\int[\mathrm{OH}] \mathrm{d} t$. Based on comparison between carbon isotope ratios and VOC concentration ratios it is also found that the varying influence of sources with different VOC emission ratios has a larger impact on VOC concentration ratios than photochemical processing. It is concluded that for this data set the use of VOC concentration ratios to determine $\int[\mathrm{OH}] \mathrm{d} t$ would result in values for $\int[\mathrm{OH}] \mathrm{d} t$ inconsistent with carbon isotope ratios and that the concept of a uniform $\int[\mathrm{OH}] \mathrm{d} t$ for an air mass has to be replaced by the concept of individual values of an average $\int[\mathrm{OH}] \mathrm{d} t$ for VOC with different reactivity.
\end{abstract}

\section{Introduction}

Anthropogenic volatile organic compounds (VOC) are important pollutants that play key roles in the production of ozone and in aerosol formation, and they significantly affect regional air quality in general. Their total annual global emission is estimated at $150 \mathrm{TgC}$ per year (Niedojadlo et al., 2008; Piccot et al., 1992). On a global scale, about 60 to $80 \%$ of anthropogenic emissions are associated with fossil fuel production, its distribution, use and storage, and up to 20 to $30 \%$ with biomass burning (Reimann and Lewis, 2007; Rudolph et al., 2002). Since anthropogenic VOC are rather diverse, classification of their emission sources is quite challenging; thus frequently these emissions are grouped according to the commodities or activities with which they are associated (Niedojadlo et al., 2008; Sawyer et al., 2000; Piccot et al., 1992; Watson et al., 1991), for instance vehicular exhaust, evaporated fuel and solvent use. Aromatic VOC are an important part of anthropogenic emissions (up to $44 \%$ ), with benzene, toluene, ethylbenzene and xylenes as major components (up to $75 \%$ ) (Jang and Kamens, 2001).

In the atmosphere many VOC undergo chemical transformation via gas-phase reactions with hydroxyl radicals $(\mathrm{OH})$, nitrate radicals $\left(\mathrm{NO}_{3}\right)$, chlorine radicals $(\mathrm{Cl})$ and ozone $\left(\mathrm{O}_{3}\right)$, with $\mathrm{OH}$ contributing the most to these oxidation processes. This oxidative processing is especially important for aromatic VOC and heavy alkanes, since it may result in the formation of oxygenated and nitrated products that may contribute to the formation of secondary organic matter (Saccon et al., 2015; Irei et al., 2006; Forstener et al., 1997).

It has been shown by many studies that the use of stable carbon isotope ratios is beneficial in providing insights 


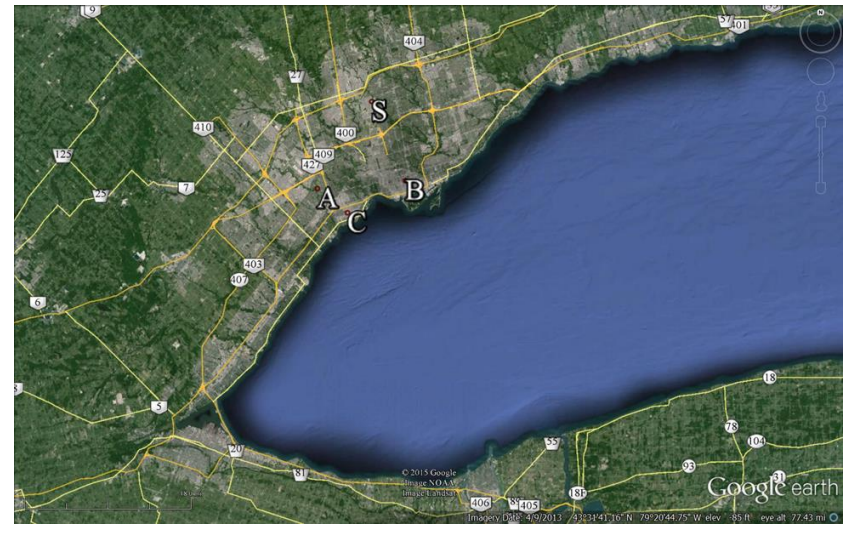

Figure 1. Location of sampling site in Toronto (S). Also shown are the locations for VOC sampling by the National Air Pollution Surveillance Program (NAPS) in Toronto (A: Elmcrest Road, Toronto, ON, Canada; B: 223 College St., Toronto, ON, Canada; C: 461 Kipling Ave., Toronto, ON, Canada). The map was produced using Google Earth $\left({ }^{\circledR}\right.$ 2015).

into photochemical transformation and physical processing of ambient volatile organic compounds (Gensch et al., 2014; Rudolph, 2007; Stein and Rudolph, 2007; Ghosh and Brand, 2003; Goldstein and Shaw, 2003; Rudolph et al., 2003, 2002; Meier-Augenstein, 1999). McKinney et al. (1950) introduced one of the first mass spectrometers able to differentiate carbon and oxygen isotopologues in carbon dioxide and oxygen molecules (Richet et al., 1977; McKinney et al., 1950). This development was followed by extensive studies of the stable carbon isotope composition of carbon monoxide, carbon dioxide and methane in ambient samples (Brenninkmeijer et al., 1995; Lowe et al., 1994; Stevens et al., 1972) and theoretical modeling and interpretations began to be presented (Brenninkmeijer et al., 1995; Kaye, 1987; Richet et al., 1977; Craig, 1953).

While some trace gases, such as methane, carbon monoxide or carbon dioxide, are present in the atmosphere at $\mu \mathrm{mol} \mathrm{mol}{ }^{-1}$ or high nmol mol${ }^{-1}$ levels and are easy to measure with state of the art isotope ratio mass spectrometry, most VOC are present at mixing ratios that are 3 to 5 orders of magnitude lower than for methane or carbon monoxide, thus making the measurement of their isotopic composition challenging. In 1997 a method which allowed the determination of stable carbon isotope composition for ambient compounds present at low mixing ratios was introduced (Rudolph et al., 1997). It was followed by isotope ratio measurements of various VOC, where it was applied and expanded (Kornilova et al., 2015a, b; Kawashima and Murakami, 2014; Wintel et al., 2013; Vitzthum-von Eckstaedt et al., 2012; Giebel et al., 2010; Redeker et al., 2007; Nara et al., 2006; Turner et al., 2006; Komatsu et al., 2005; Czapiewski et al., 2002; Rudolph et al., 2002; Saito et al., 2002). Still, the number of publications containing measurements of isotope ra-
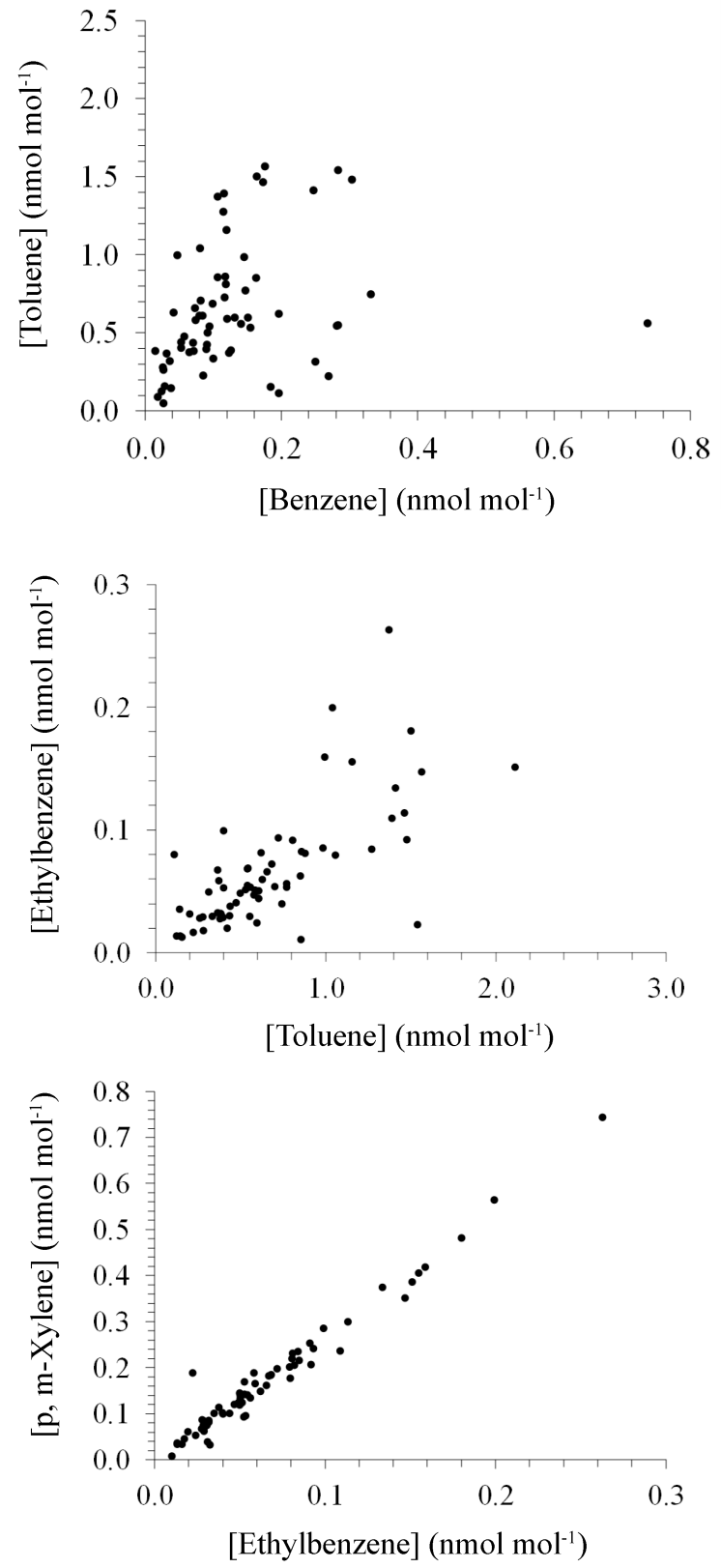

Figure 2. Example plots for the dependence between mixing ratios for different VOC pairs.

tios of ambient VOC and their sources is very limited (Kornilova et al., 2015b; Gensch et al., 2014; Elsner et al., 2012).

The stable carbon isotope ratio is determined by the ratio of ${ }^{13} \mathrm{C}$ to ${ }^{12} \mathrm{C}$ atoms in the sample and is usually expressed in delta notation $\left(\delta^{13} \mathrm{C}\right)$ relative to a reference value (Vienna Peedee Belemnite, VPDB) with ${ }^{13} \mathrm{C} /{ }^{12} \mathrm{C}$ $=0.0112372$; Craig, 1953). Since changes in ${ }^{13} \mathrm{C} /{ }^{12} \mathrm{C}$ are small, $\delta^{13} \mathrm{C}$ is expressed in parts per thousand (\%o) (Eq. 1). 
Table 1. Performance of the system for analysis of volatile organic compounds in ambient air.

\begin{tabular}{lccc}
\hline Compound & $\begin{array}{c}\text { Detection limit } \\
(\mathrm{ng})\end{array}$ & $\begin{array}{c}\text { Relative precision in concentration } \\
\text { measurement } \\
(\%)\end{array}$ & $\begin{array}{c}\text { Precision in } \\
\delta^{13} \text { C measurement }^{\mathrm{c}} \\
(\%))\end{array}$ \\
\hline Benzene & 1.5 & 4 & 0.3 \\
Toluene & 0.4 & 4 & 0.2 \\
Ethylbenzene & 0.6 & 6 & 0.2 \\
$o$-Xylene & 0.4 & 8 & 0.3 \\
$p, m$-Xylene & 0.5 & 9 & 0.3 \\
\hline
\end{tabular}

${ }^{\text {a }}$ Detection limit calculated using $3 \sigma$, where $\sigma$ is the standard deviation of blank values determined from 3 to 4 repeat measurements. ${ }^{b}$ Precision calculated as relative standard deviation (\%) of peak area for $>10$ repeat measurements.

${ }^{\mathrm{c}}$ Precision calculated as standard deviation of $\delta^{13} \mathrm{C}$ values for $>10$ repeat measurements.

$\delta^{13} \mathrm{C}=\frac{R_{\text {sample }}\left({ }^{13} \mathrm{C} /{ }^{12} \mathrm{C}\right)-R_{\mathrm{VPDB}}\left({ }^{13} \mathrm{C} /{ }^{12} \mathrm{C}\right)}{R_{\mathrm{VPDB}}\left({ }^{13} \mathrm{C} /{ }^{12} \mathrm{C}\right)} \times 1000 \%$

The presence of ${ }^{13} \mathrm{C}$ isotopes slightly affects the reaction rate of the molecule, as ${ }^{13} \mathrm{C}$ containing isotopologues react slower than ${ }^{12} \mathrm{C}$-only isotopologues. The relative difference between these rate constants $\left({ }^{12} k\right.$ and $\left.{ }^{13} k\right)$, known as kinetic isotope effect (KIE), is expressed in epsilon notation $(\varepsilon)$ in parts per thousand (\%o) (Eq. 2).

$\varepsilon_{\mathrm{OH}}=\frac{{ }^{12} k-{ }^{13} k}{{ }^{13} k} \times 1000 \%$

Since ${ }^{12} \mathrm{C}$ is more reactive, the sample gets enriched in ${ }^{13} \mathrm{C}$ with time and the magnitude of this depends on the extent of processing as well as the KIE.

The term "photochemical age" is used for quantification of photochemical processing of a compound and it is usually defined as the time integral of the $\mathrm{OH}$ concentration $\left(\int[\mathrm{OH}] \mathrm{d} t\right)$. Originally VOC concentration ratios were used to determine $\int[\mathrm{OH}] \mathrm{d} t$, an approach that often is referred to as hydrocarbon clock (Kornilova et al., 2015b; Stein and Rudolph, 2007; Kleinman et al., 2003; Rudolph et al., 2003; Thompson et al., 2003; Rudolph and Czuba, 2000; Jobson et al., 1999, 1998). This concept implies that $\int[\mathrm{OH}] \mathrm{d} t$ is identical for the VOC used for the calculation and sometimes the term photochemical history of air masses is used (Parrish et al., 1992). The isotope hydrocarbon clock approach is similar but uses stable carbon isotope ratios (Rudolph and Czuba, 2000) (Eq. 3):

$\int[\mathrm{OH}] \mathrm{d} t=\frac{\delta_{\mathrm{A}}{ }^{13} \mathrm{C}-\delta_{\mathrm{S}}{ }^{13} \mathrm{C}}{k_{\mathrm{OH}} \varepsilon_{\mathrm{OH}}}$,

where $\int[\mathrm{OH}] \mathrm{d} t$ is the average photochemical age, $\delta_{\mathrm{A}}^{13} \mathrm{C}$ and $\delta_{\mathrm{S}}^{13} \mathrm{C}$ are the stable carbon isotope compositions of ambient and freshly emitted VOC respectively, $k_{\mathrm{OH}}$ is the rate constant for the reaction of VOC and $\mathrm{OH}$, and $\varepsilon_{\mathrm{OH}}$ is the KIE (Eq. 2). Since this approach only uses one compound for calculating $\int[\mathrm{OH}] \mathrm{d} t$ it is possible to determine an average value of $\int[\mathrm{OH}] \mathrm{d} t$ for individual VOC.
In this paper we present stable carbon isotope ratios of ambient aromatic VOC measured at a suburban area in 2009 and 2010. The results will be used to determine $\int[\mathrm{OH}] \mathrm{d} t$ for VOC with different reactivity and to determine the impact of photochemical processing on the change in VOC concentration ratios.

\section{Materials and method}

Selective VOC sampling from ambient air was done using cartridges (13 to $15 \mathrm{~cm}$ long, $1 / 4$ in. OD) filled with Carboxene 569, a mass flow controller and a diaphragm pump with a sampling flow rate set between 10 and $50 \mathrm{~mL} \mathrm{~min}^{-1}$ as described in detail by Kornilova et al. (2015a). VOC were quantitatively extracted from cartridges using a thermal desorption unit with helium as a carrier gas (60 to $\left.80 \mathrm{~mL} \mathrm{~min}^{-1}\right)$ at $553 \mathrm{~K}$ for $40 \mathrm{~min}$. Desorbed VOC were focused using a twostage preconcentration system. Compounds were then separated using a HP5890 Series II gas chromatograph equipped with a DB- 1 column $(100 \mathrm{~m}, 0.25 \mathrm{~mm}$ ID, $0.5 \mu \mathrm{m}$ film thickness). Separated compounds were directed to a combustion interface ( $1 / 4 \mathrm{in}$. OD, $0.5 \mathrm{~mm}$ ID, $44 \mathrm{~cm}$ long ceramic tube with copper, nickel and platinum wires inside) where they were converted to $\mathrm{H}_{2} \mathrm{O}$ and $\mathrm{CO}_{2} . \mathrm{H}_{2} \mathrm{O}$ was removed by Nafion tubing, while $\mathrm{CO}_{2}$ was directed into an isotope ratio mass spectrometer (IRMS) where $\mathrm{m} / \mathrm{z} 44,45$ and 46 were analyzed. Performance characteristics of the sampling and analysis procedures discussed by Kornilova et al. (2015a) are summarized in Table 1 . The accuracy of $\delta^{13} \mathrm{C}$ measurements was $0.5 \%$ for sample masses exceeding $3 \mathrm{ng}$ of the target compound. For a typical $24 \mathrm{~h}$ sample this mass corresponds to an atmospheric mixing ratio of 20 to $30 \mathrm{pmol} \mathrm{mol}^{-1} \cdot \delta^{13} \mathrm{C}$ results are not reported here for sample masses that were lower than this.

Ambient VOC were collected at a site located in the northern part of the Greater Toronto Area (GTA) on the premises of the Downsview location of Environment Canada $\left(43^{\circ} 46^{\prime} \mathrm{N}, 79^{\circ} 28^{\prime} \mathrm{W}\right.$ ) from 2009 to 2010 (Fig. 1). Samples were collected from Monday to Thursday over $24 \mathrm{~h}$ time 

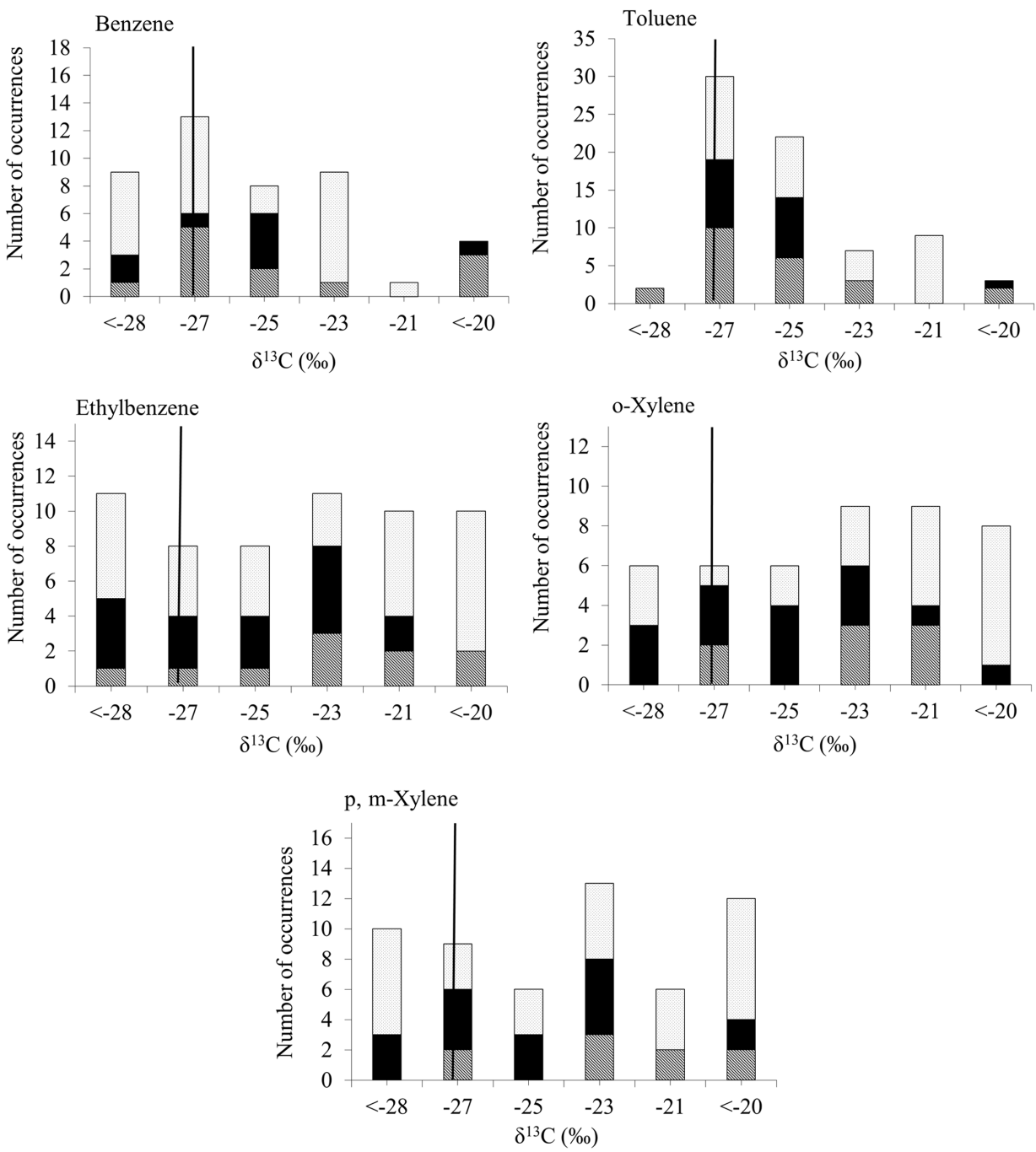

Figure 3. Frequency distribution for VOC carbon isotope ratios measured in Toronto in 2009 and 2010. Observations for different seasons are identified as follows: fall - dotted; winter - black; spring and summer - hatched. The solid vertical lines are the isotope composition of traffic-related emissions (Rudolph et al., 2002).

Table 2. Mixing ratios (nmol mol${ }^{-1}$ ) determined for volatile organic compounds collected in Toronto (2009-2010).

\begin{tabular}{lcccccccc}
\hline Compound & $N^{\mathrm{a}}$ & Mean & $s^{\mathrm{b}}$ & Median & Minimum & Maximum & 90th percentile & 10th percentile \\
\hline Benzene & 65 & 0.13 & 0.12 & 0.11 & 0.02 & 0.74 & 0.28 & 0.03 \\
Toluene & 73 & 0.64 & 0.44 & 0.56 & 0.05 & 2.11 & 1.39 & 0.16 \\
Ethylbenzene & 69 & 0.07 & 0.05 & 0.05 & 0.01 & 0.26 & 0.14 & 0.02 \\
$o$-Xylene & 66 & 0.05 & 0.03 & 0.04 & 0.01 & 0.17 & 0.10 & 0.01 \\
$p, m$-Xylene & 68 & 0.17 & 0.13 & 0.14 & 0.01 & 0.74 & 0.36 & 0.04 \\
\hline
\end{tabular}

${ }^{a}$ Number of measurements. ${ }^{b}$ Sample standard deviation.

periods (07:00 to 07:00), Friday sampling lasted 6 to $8 \mathrm{~h}$ (07:00 to 16:00) and Friday to Sunday samples were collected over $64 \mathrm{~h}$ (16:00 on Friday to 07:00 on Monday). Most samples were collected between fall 2009 and winter 2010 (October 2009 to February 2010), with some additional samples collected in March 2010, and from August 2010 to September 2010. The average sampling flow rate was 24 to $25 \mathrm{~mL} \mathrm{~min}^{-1}$. In total, 74 samples were analyzed for VOC concentrations and carbon isotope ratios, although in several 
Table 3. Average mixing ratios (nmol mol${ }^{-1}$ ) calculated from data reported by the National Air Pollution Surveillance Program (NAPS) for three locations in Toronto during the time periods covered in this work.

\begin{tabular}{|c|c|c|c|c|c|c|c|c|}
\hline \multirow{2}{*}{$\begin{array}{l}\text { Location } \\
\text { Compound }\end{array}$} & \multicolumn{2}{|c|}{ Etobicoke West $^{\mathrm{a}}$} & \multicolumn{2}{|c|}{ Downtown Toronto ${ }^{b}$} & \multicolumn{2}{|c|}{ Etobicoke South $^{\mathrm{c}}$} & \multicolumn{2}{|c|}{ This work } \\
\hline & mean & $s^{\mathrm{d}}$ & mean & $s^{\mathrm{d}}$ & mean & $s^{\mathrm{d}}$ & mean & $s^{\mathrm{d}}$ \\
\hline Benzene & 0.18 & 0.07 & 0.23 & 0.10 & 0.20 & 0.10 & 0.13 & 0.12 \\
\hline Toluene & 0.49 & 0.31 & 0.62 & 0.55 & 0.68 & 0.65 & 0.64 & 0.44 \\
\hline Ethylbenzene & 0.06 & 0.04 & 0.07 & 0.04 & 0.09 & 0.06 & 0.07 & 0.05 \\
\hline$o$-Xylene & 0.05 & 0.04 & 0.07 & 0.04 & 0.07 & 0.05 & 0.05 & 0.03 \\
\hline$p, m$-Xylene & 0.18 & 0.13 & 0.23 & 0.13 & 0.27 & 0.21 & 0.17 & 0.13 \\
\hline
\end{tabular}

a Elmcrest Road, Toronto, ON, Canada. ${ }^{\mathrm{b}} 223$ College S., Toronto, ON, Canada. ${ }^{c} 461$ Kipling Ave., Toronto, ON, Canada. ${ }^{\text {d Sample }}$ standard deviation.

Table 4. Linear regression analysis of mixing ratio correlations. Values above the diagonal are $R^{2}$ and below are the intercepts ${ }^{\mathrm{a}}$.

\begin{tabular}{lrrrrr}
\hline & Benzene $^{\mathrm{b}}$ & Toluene & Ethylbenzene & $o$-Xylene & $p, m$-Xylene \\
\hline Benzene $^{\mathrm{b}}$ & & $<0.3$ & $<0.3$ & $<0.3$ & $<0.3$ \\
Toluene & NA & & 0.495 & 0.586 & 0.488 \\
Ethylbenzene & NA & $0.011(0.008)$ & & 0.825 & 0.964 \\
$o$-Xylene & NA & $0.003(0.006)$ & $0.008(0.003)$ & & 0.877 \\
$p, m$-Xylene & NA & $0.020(0.023)$ & $-0.007(0.005)$ & $-0.014(0.011)$ & \\
\hline
\end{tabular}

${ }^{\text {a }}$ Standard error of intercept $\left(\mathrm{nmol} \mathrm{mol}^{-1}\right)$ in parenthesis. The values are for linear fits of the mixing ratio of the more reactive VOC vs. the mixing ratio of the less reactive VOC. ${ }^{b}$ No significant correlation was found for linear regressions of the mixing ratios of any of the VOC vs. the mixing ratios of benzene. $\mathrm{NA}=$ not available

of those samples carbon isotope ratios could only be determined for some of the target compounds.

\section{Results and discussion}

\subsection{Overview}

Averages and some basic statistics for concentrations of ambient aromatic VOC collected in Toronto (2009 to 2010) are summarized in Table 2. Mixing ratios determined for the targeted VOC are in the low to mid $\mathrm{pmol} \mathrm{mol}^{-1}$ range and are similar to mixing ratios reported by Canada's National Air Pollution Surveillance Program (NAPS, data taken from data base for years 2009-2010) for downtown Toronto and two suburban locations in Toronto (Table 3). The observed mixing ratios are also within the range of values reported in several measurement series at various locations in North America (Kornilova et al., 2015b; Jobson et al., 2004; Pankow et al., 2003; Riemer et al., 1998; Hagerman et al., 1997; Roberts et al., 1984).

Except for benzene, the VOC mixing ratios are linearly correlated with each other with $y$ axis intercepts close to 0 . Except for the linear correlation between the mixing ratios of ethylbenzene and $o$-xylene, the $y$ axis intercept is statistically not different from 0 (95\% confidence interval) (Table 4, Fig. 2). The VOC concentration ratios observed are within or close to the range of values reported in literature. Exceptions are the toluene over benzene ratio and the $p, m$-xylene over $o$-xylene ratio, which are higher than previously reported ratios (Table 5) but similar to the ratios that can be derived from the NAPS data reported for other locations in Toronto in Table 3.

Averages and basic statistics for measured carbon isotope ratios are summarized in Table 6 . The majority of the determined $\delta^{13} \mathrm{C}$ values are comparable with those observed in other ambient studies (Table 7). The only exception is the value reported by Redeker et al. (2007) for benzene, which is about $3 \%$ lighter than the average for our measurements and close to the 10th percentile of our observations.

Figure 3 shows the frequency distribution for the measured carbon isotope ratios. The lower end of the distribution is close to the carbon isotope ratios reported in literature for their emissions (Table 8). The only exceptions are the benzene and toluene carbon isotope ratios reported by Turner et al. (2006) for industrial stack emissions, which are about 3 to $5 \%$ o heavier than the lower end of our observations. Turner et al. (2006) reported no details of the type of industrial emissions studied and therefore the possible impact of such heavier industrial emissions on ambient carbon isotope ratios cannot be evaluated. Only 13 of our 275 measured carbon isotope ratios are significantly below the carbon isotope ratios reported by Rudolph et al. (2002) for emissions in Toronto, whereas 186 observations are significantly heavier $(95 \%$ confidence limit determined from the uncertainty of the emission ratios and measurement errors). 
Table 5. Ratios of VOC mixing ratios. Values below the diagonal are the ratios for the measurements presented in this work ${ }^{\mathrm{a}}$, values above the diagonal give the range of ratios observed in literature ${ }^{\mathrm{b}}$.

\begin{tabular}{lrrrrr}
\hline & Benzene & Toluene & Ethylbenzene & $o$-Xylene & $p, m$-Xylene \\
\hline Benzene & & $1.5-3.7$ & $0.11-1.2$ & $0.23-3.2$ & $0.46-0.3 .8$ \\
Toluene & $6.6(0.6)$ & & $0.07-0.35$ & $0.14-0.86$ & $0.27-1.1$ \\
Ethylbenzene & $0.69(0.08)$ & $0.080(0.01)$ & & $0.6-2.1$ & $1.2-4.3$ \\
$o$-Xylene & $0.52(0.07)$ & $0.069(0.007)$ & $0.64(0.04)$ & & $1.7-2.9$ \\
$p, m$-Xylene & $1.8(0.2)$ & $0.22(0.003)$ & $2.7(0.07)$ & $3.7(0.2)$ & \\
\hline
\end{tabular}

${ }^{a}$ Standard error of ratios in parenthesis. The ratios are for the mixing ratio of the more reactive VOC over the mixing ratio of the less reactive VOC. For compounds with correlated mixing ratios, the slope of the linear regressions and standard errors of the slopes are given; in the absence of correlation, the average of the ratios and standard error of average ratios are given. ${ }^{b}$ Range of observations in urban, residential and commercial areas reported by Hoque et al. (2008), Karl et al. (2009), Miller et al. (2011), Alghamdi et al. (2014), de Gennaro et al. (2015) and Rad et al. (2014).

Table 6. Stable carbon isotope composition $\left(\delta^{13} \mathrm{C}, \%\right.$ o $)$ of ambient VOC collected in Toronto (2009-2010).

\begin{tabular}{lcrrrrrr}
\hline Compound & $N^{\mathrm{a}}$ & Mean & $s^{\mathrm{b}}$ & Median & Range & 10th percentile & 90th percentile \\
\hline Benzene & 44 & -25.0 & 3.4 & -26.0 & -39.4 to -13.6 & -28.4 & -20.9 \\
Toluene & 73 & -24.8 & 3.2 & -25.7 & -28.5 to -7.7 & -27.4 & -20.5 \\
Ethylbenzene & 58 & -24.0 & 4.0 & -23.4 & -34.8 to -17.4 & -28.5 & -18.8 \\
$o$-Xylene & 44 & -23.3 & 3.5 & -23.3 & -30 to -16.5 & -28.0 & -18.4 \\
$p, m$-Xylene & 56 & -24.0 & 4.1 & -23.8 & -34.6 to -16.4 & -28.4 & -18.9 \\
\hline
\end{tabular}

${ }^{\mathrm{a}}$ Number of measurements. ${ }^{\mathrm{b}}$ Sample standard deviation.

Overall, there is little systematic change of the carbon isotope ratios with season (Fig. 3). The only significant exceptions are the carbon isotope ratios of the $\mathrm{C}_{2}$-alkylbenzenes, which are approximately $2 \%$ lighter in spring and fall compared to summer and winter ( $t$ test, $99.9 \%$ probability).

There is a strong dependence between carbon isotope ratios of ethylbenzene and $o$-xylene, ethylbenzene and $p, m$ xylene as well as $o$-xylene and $p, m$-xylene. The correlations between the carbon isotope ratio of toluene and the $\mathrm{C}_{2}$ alkylbenzenes are only weak and no correlation between the carbon isotope ratios of benzene and any of the other aromatic VOC is found (Fig. 4, Table 9). None of the $y$ axis intercepts of the linear regressions are significantly different from 0 (95\% confidence interval), which is consistent with the finding that the carbon isotope ratios of emissions for different aromatic VOC are similar (Rudolph et al., 2002). There is no clear dependence between mixing ratios and carbon isotope ratios (Fig. 5), although in some cases the mixing ratios on average differed for different ranges of carbon isotope ratios (see below).

\subsection{Ambient carbon isotope ratios and atmospheric VOC processing}

The observed carbon isotope ratios cover a range of more than $8 \%$ (Fig. 3), which cannot be explained by measurement errors (Table 1) or uncertainty of the carbon isotope ratios of known VOC sources (Table 8). Although the existence of unidentified sources of VOC with very heavy car- bon isotope ratios cannot be completely ruled out, it is unlikely that this could explain the observed variability of measured carbon isotope ratios since such an unidentified source would have to be of approximately the same magnitude as the known sources to explain the absence of a systematic dependence between VOC carbon isotope ratio and VOC mixing ratios (Fig. 5).

Anderson et al. (2004b) reported that the reaction of aromatic VOC with the $\mathrm{OH}$ radical, which is the dominant loss process for light aromatic VOC in the atmosphere, results in enrichment of ${ }^{13} \mathrm{C}$ in the residual VOC. Variations in the extent of reaction with $\mathrm{OH}$ radicals can therefore explain the observed variability of carbon isotope ratios as well as the absence of a significant number of $\delta^{13} \mathrm{C}$ values lower than the $\delta^{13} \mathrm{C}$ values of emissions (Table 8). Table 10 summarizes the rate constants and KIEs for the reaction of the studied compounds with the $\mathrm{OH}$ radical as well as the $\delta^{13} \mathrm{C}$ values reported for their emissions in Toronto by Rudolph et al. (2002). Included in Table 10 are also the $\delta^{13} \mathrm{C}$ values calculated from $\delta^{13} \mathrm{C}_{\text {steady state }}=\delta^{13} \mathrm{C}_{\text {emissions }}+\varepsilon_{\mathrm{OH}}$. Here $\delta^{13} \mathrm{C}_{\text {steady state }}$ is the hypothetical average carbon isotope ratio of an atmospheric VOC in steady state between emissions and loss by reaction with the $\mathrm{OH}$ radical. For comparison the average of measured $\delta^{13} \mathrm{C}$ values is also given in Table 11.

The averages of the measured $\delta^{13} \mathrm{C}$ values are consistently lighter than the predictions for steady state. However, only for toluene and benzene, the least reactive of the light aro- 
Table 7. Average and standard deviation of reported stable carbon isotope composition measurements $\left(\delta^{13} \mathrm{C}, \%\right.$ o $)$ of ambient light aromatic VOC $^{\mathrm{a}}$.

\begin{tabular}{lrrrrr}
\hline Location & Benzene & Toluene & Ethylbenzene & $o$-Xylene & $p, m$-Xylene \\
\hline Toronto $^{\mathrm{b}}$ & $-24.6(2.3)$ & $-25.0(1.1)$ & $-25.3(2.7)$ & $-24.9(1.5)$ & $-25.6(1.0)$ \\
Belfast $^{\mathrm{c}}$ & $-23.8(2.5)$ & $-26.9(0.9)$ & $-26.5(1.4)$ & $-26.3(1.3)$ & $-27.4(1.7)$ \\
Crossgar and Hillsborough $^{\mathrm{d}}$ & $-28.3(1.7)$ & & & & \\
Southwestern Germany $^{\mathrm{e}}$ & & -27 to -23 & & & \\
Egbert $^{\mathrm{f}}$ & $-25.3(2.6)$ & $-24.8(1.7)$ & $-23.7(3.6)$ & $-23.4(2.6)$ & $-23.8(3.0)$ \\
Yurihonjo $^{\text {g Japan) }}$ & & & -29.6 to -23.5 & & \\
\hline
\end{tabular}

\footnotetext{
${ }^{a}$ Sample standard deviation is given in parenthesis. ${ }^{b}$ Urban Canada (Rudolph et al., 2002). ${ }^{c}$ Urban Northern Ireland (Redeker et al., 2007).

${ }^{\mathrm{d}}$ Rural Northern Ireland (Redeker et al., 2007). ${ }^{\mathrm{e}}$ Vertical profile over rural area; only range of data available (Wintel et al., 2013). ${ }^{\mathrm{f}}$ Rural

Canada (Kornilova et al., 2015b). ${ }^{\mathrm{g}}$ Urban Japan; only range of data available (Kawashima and Murakami, 2014).
}

Table 8. Average stable carbon isotope ratios $\left(\delta^{13} \mathrm{C}, \%\right.$ o $)$ of major sources of ambient VOC. The sample standard deviation is given in parenthesis.

\begin{tabular}{|c|c|c|c|c|c|}
\hline Source & Benzene & Toluene & Ethylbenzene & $o$-Xylene & $p, m$-Xylene \\
\hline Gasoline $^{\mathrm{a}}$ & $-27.0(-24.5 \text { to }-29.9)^{b}$ & $-26.0,-28.1^{b}$ & $-27.4(2.8)$ & $-26.5(1.9)$ & $-27.9(1.2)$ \\
\hline Tunnel $^{\mathrm{c}}$ & $-26.5(1.0)$ & $-27.5(1.0)$ & $-27.4(0.9)$ & $-27.3(0.4)$ & $-26.9(2.0)$ \\
\hline Gas station $^{\mathrm{c}}$ & $-29.1(0.3)$ & $-27.4(0.6)$ & $-28.2(0.4)$ & $-27.1(0.6)$ & $-27.7(0.5)$ \\
\hline Gas station $^{\mathrm{d}}$ & $-27.35(1.6)$ & $-27.08(0.7)$ & $-26.48(1.6)$ & & $-27.4(0.8)$ \\
\hline Underground garage $^{\mathrm{c}}$ & $-27.7(0.7)$ & $-27.1(0.7)$ & $-27.5(1.1)$ & $-27.2(1.1)$ & $-27.7(1.0)$ \\
\hline Biomass burning $\mathrm{e}^{\mathrm{r}}$ & $-26.0(0.1)$ & $-26.5(0.9)$ & $-25.7(0.5)$ & & \\
\hline Biomass burning $f$ & $-27.6(1.6)$ & $-27.1(1.3)$ & & & \\
\hline Fossil fuel combustion $f$ & $-26.9(0.3)$ & $-27.5(0.6)$ & & & \\
\hline Industrial stack ${ }^{\mathrm{g}}$ & $-23.5(0.11)$ & $-25.4(0.48)$ & & & \\
\hline
\end{tabular}

a Averages and standard deviations were calculated from the results of analysis of four individual gasoline samples reported by Smallwood et al. (2002). ${ }^{\mathrm{b}}$ For benzene only, average and range are available; for toluene only two individual values were reported. ${ }^{\mathrm{c}}$ Rudolph et al. (2002). ${ }^{\mathrm{d}}$ Kawashima and Murakami (2014). ${ }^{\mathrm{e}}$ Czapiewski et al. (2003). ${ }^{\mathrm{f}}$ Giebel et al. (2010). ${ }^{\mathrm{g}}$ Turner et al. (2006).

matic VOC, this difference is statistically significant at the $99 \%$ confidence level. Since the measurements were made at a location impacted by substantial emissions within a less than $10 \mathrm{~km}$ radius it is not surprising that for VOC with a short atmospheric residence time the average carbon isotope ratio is closer to a steady state between emission and removal reaction than for less reactive VOC. Indeed, the Pearson product moment correlation coefficient for the difference between steady state and average measured isotope ratios and atmospheric residence time is 0.863 and the $R^{2}$ for a linear correlation is 0.745 . However, this is only based on data for five different compounds and the average of the carbon isotope ratios is the result of isotope ratio measurements covering a wide range of $\delta^{13} \mathrm{C}$ values (Fig. 3).

Table 11 shows a breakdown of measured $\delta^{13} \mathrm{C}$ values into different ranges by compound. The number of observations with $\delta^{13} \mathrm{C}$ values heavier than steady state between emission and removal is in the range of $25 \%$ for the $\mathrm{C}_{2}$-alkylbenzenes whereas for toluene less than $10 \%$ of the observations fall into this range. For benzene, by far the least reactive of the studied VOC, the percentage of data points close to steady state $\delta^{13} \mathrm{C}$ values is even smaller. There is no systematic de- pendence between the percentages of $\delta^{13} \mathrm{C}$ values close to the source isotope ratios and VOC reactivity. This is compatible with the concept that photochemical aging is an important process resulting in changes in the carbon isotope ratios of ambient VOC as well as the predicted dependence between carbon isotope ratio and the rate constant for the atmospheric VOC removal reactions (Eq. 3).

In principle these findings are similar to the change in VOC concentration ratios as result of photochemical processing, which has been used to study and quantify photochemical VOC processing in the atmosphere (Kleinman et al., 2003; Jobson et al., 1999, 1998; Parrish et al., 1992; Rudolph and Johnen, 1990). It has been shown that the $\int[\mathrm{OH}] \mathrm{d} t \mathrm{de}-$ termined from $\delta^{13} \mathrm{C}$ values of $\mathrm{VOC}$ is a valid approximation for the age of the studied VOC even in the case of mixing air masses with different values for $\int[\mathrm{OH}] \mathrm{d} t$ (Rudolph and Czuba, 2000), whereas the use of VOC concentration ratios to quantify $\mathrm{VOC}$ processing requires an identical $\int[\mathrm{OH}] \mathrm{d} t$ for VOC with different reactivity (Rudolph and Johnen, 1990), a condition that often is referred to as photochemical age of the air mass (Parrish et al., 1992). The validity of the assumption of an identical $\int[\mathrm{OH}] \mathrm{d} t$ for VOC of different 
Table 9. Regression analysis of delta values. Values above diagonal are $R^{2}$, and those below are the intercepts.

\begin{tabular}{lrrrrr}
\hline & Benzene $^{\mathrm{b}}$ & Toluene & Ethylbenzene & $o$-Xylene & $p, m$-Xylene \\
\hline Benzene $^{\mathrm{b}}$ & & $<0.3$ & $<0.3$ & $<0.3$ & $<0.3$ \\
Toluene & $\mathrm{NA}$ & & 0.361 & 0.356 & 0.335 \\
Ethylbenzene & $\mathrm{NA}$ & $-0.04(4.31)^{\mathrm{a}}$ & & 0.820 & 0.963 \\
$o$-Xylene & $\mathrm{NA}$ & $-2.58(4.31)$ & $-2.54(1.56)$ & & 0.825 \\
$p, m$-Xylene & NA & $-0.49(4.57)$ & $-0.19(0.64)$ & $-1.64(1.63)$ & \\
\hline
\end{tabular}

a Standard error of intercept $(\% o$ ) in parenthesis. The values are for linear fits of the mixing ratio of the more reactive VOC vs. the mixing ratio of the less reactive VOC. ${ }^{b}$ No significant correlation was found for linear regressions of the mixing ratios of any of the VOC vs. the mixing ratios of benzene.

Table 10. Summary of kinetic data, carbon isotope ratio of emissions, carbon isotope ratio calculated for steady state between emission and loss, and average measured carbon isotope ratio for light aromatic VOC ${ }^{\mathrm{a}}$.

\begin{tabular}{lrrrrr}
\hline Compound & $\begin{array}{r}k_{\mathrm{OH}}^{\mathrm{b}} \\
\left(10^{-12} \mathrm{~cm}^{3} \mathrm{molec}^{-1} \mathrm{~s}^{-1}\right)\end{array}$ & $\begin{array}{r}\varepsilon_{\mathrm{OH}} \\
(\% \circ)^{\mathrm{c}}\end{array}$ & $\begin{array}{r}\delta^{13} \mathrm{C} \text { source } \\
(\% \circ)^{\mathrm{d}}\end{array}$ & $\begin{array}{r}\delta^{13} \mathrm{C} \text { steady } \\
\text { state }(\% o)\end{array}$ & $\begin{array}{r}\text { Average of } \delta^{13} \mathrm{C} \\
\text { measured }(\% o)\end{array}$ \\
\hline Benzene & 1.22 & $7.83(0.42)^{\mathrm{e}}$ & $-28.0(0.2)$ & $-20.1(0.5)$ & $-25.0(0.5)$ \\
Toluene & 5.63 & $5.59(0.28)$ & $-27.6(0.5)$ & $-21.7(0.5)$ & $-24.8(0.4)$ \\
Ethylbenzene & 7.0 & $4.34(0.28)$ & $-27.7(0.2)$ & $-23.4(0.4)$ & $-24.0(0.5)$ \\
$o$-Xylene & 13.6 & $4.27(0.05)$ & $-27.2(0.2)$ & $-22.9(0.2)$ & $-23.3(0.5)$ \\
$p, m$-Xylene & $20.5^{\mathrm{f}}$ & $4.83(0.05)^{\mathrm{g}}$ & $-27.4(0.4)$ & $-22.6(0.4)$ & $-24.0(0.6)$ \\
\hline
\end{tabular}

${ }^{a}$ Values in parenthesis are the standard error of the mean. ${ }^{b}$ Rate constants for $298 \mathrm{~K}$ (Atkinson and Arey, 2003; Finlayson-Pitts and Pitts, 2000).

${ }^{c}$ Carbon kinetic isotope effects for reaction with OH radicals (Anderson et al., 2004a, b; Rudolph et al., 2002). ${ }^{\mathrm{d}}$ Isotopic composition of

traffic-related VOC emissions in Toronto (Rudolph et al., 2002). ${ }^{\mathrm{e}}$ Average $\varepsilon$ calculated from 8.13 (0.8) (Anderson et al., 2004b) and $7.53(0.5)$ (Rudolph et al., 2002). ${ }^{\mathrm{f}}$ Average of $k_{\mathrm{OH} p \text {-xylene }}=1.43 \times 10^{-11} \mathrm{~cm}^{3} \mathrm{molec}^{-1} \mathrm{~s}^{-1}$ and $k_{\mathrm{OH} m \text {-xylene }}=2.36 \times 10^{-11} \mathrm{~cm}^{3} \mathrm{molec}^{-1} \mathrm{~s}^{-1} . \mathrm{g}_{\varepsilon_{\mathrm{OH}}}$ $(\%)$ is for $p$-xylene; no value is available for $\mathrm{m}$-xylene.

reactivity can be tested by a comparison of carbon isotope ratios predicted by Eq. (3) for identical $\int[\mathrm{OH}] \mathrm{d} t$ :

$\frac{\delta_{\mathrm{A}}^{\mathrm{A} 13} \mathrm{C}-\delta_{\mathrm{S}}^{\mathrm{A} 13} \mathrm{C}}{\delta_{\mathrm{A}}^{\mathrm{B} 13} \mathrm{C}-\delta_{\mathrm{S}}^{\mathrm{B} 13 \mathrm{C}}}=\frac{k_{\mathrm{OH}}^{\mathrm{A}} \varepsilon_{\mathrm{OH}}^{\mathrm{A}}}{k_{\mathrm{OH}}^{\mathrm{B}} \varepsilon_{\mathrm{OH}}^{\mathrm{B}}}$.

In Table 12 the slopes calculated for identical values for the average $\int[\mathrm{OH}] \mathrm{d} t$ of different VOC are compared with the slopes determined from linear regression of measured carbon isotope ratios. With the exception of the dependence between toluene and ethylbenzene, which have similar reactivity towards the $\mathrm{OH}$ radical, the calculated slopes differ substantially from the observed slopes demonstrating that the assumption of an identical $\int[\mathrm{OH}] \mathrm{d} t$ for VOC with different reactivity is not valid. This strongly points towards mixing air masses containing VOC with different values for $\int[\mathrm{OH}] \mathrm{d} t$. This is consistent with the location of the sampling site at the outskirts of a major city and a sampling duration that lasted at least several hours, in most cases about 1 day.

\subsection{Photochemical age and mixing of air masses}

Carbon isotope ratios of VOC allow calculation of the average $\int[\mathrm{OH}] \mathrm{d} t$ of the individual volatile organic compound without the requirement of a uniform $\int[\mathrm{OH}] \mathrm{d} t$ and therefore our observations can be used to determine the $\int[\mathrm{OH}] \mathrm{d} t$ of VOC with different atmospheric lifetime independent of assumptions about atmospheric mixing. Table 13 lists basic statistics for the values of $\int[\mathrm{OH}] \mathrm{d} t$ determined from our $\delta^{13} \mathrm{C}$ measurements based on Eq. (3) using the kinetic data and carbon isotope ratios of VOC emissions listed in Table 10 .

Due to the uncertainty of the carbon isotope ratios of emissions and measurement errors, low values of $\int[\mathrm{OH}] \mathrm{d} t$ have large relative uncertainty. The consequence is a substantial number of negative $\int[\mathrm{OH}] \mathrm{d} t$ values. Nevertheless, out of the $275 \int[\mathrm{OH}] \mathrm{d} t$ values only 13 are below 0 at a $95 \%$ confidence limit determined from the uncertainty of the $\int[\mathrm{OH}] \mathrm{d} t$ whereas 166 of the $\int[\mathrm{OH}] \mathrm{d} t$ values are significantly larger than 0 (95\% confidence limit).

The values for average $\int[\mathrm{OH}] \mathrm{d} t$ of the different VOC differ substantially. The highest average $\int[\mathrm{OH}] \mathrm{d} t$ of $3.1 \times$ $10^{11} \mathrm{~s}$ molecules $\mathrm{cm}^{-3}$ is found for benzene, whereas the average $\int[\mathrm{OH}] \mathrm{d} t$ for the most reactive VOC is only $3.4 \times$ $10^{10} \mathrm{~s}$ molecules $\mathrm{cm}^{-3}$ (Table 13). There is strong evidence for a systematic dependence between atmospheric residence time and average $\int[\mathrm{OH}] \mathrm{d} t$ (Fig. 6). The Pearson product moment correlation coefficient for the dependence between $\int[\mathrm{OH}] \mathrm{d} t$ and atmospheric residence time is 0.981 and $R^{2}$ for a linear fit is 0.963 . The correlation is strongly influenced by the data point for the benzene. When excluding this data point the Pearson product moment correlation coefficient is 0.760 and $R^{2}$ for a linear fit is 0.578 . The finding of differ- 
Table 11. Overview of the number of observations within different ranges of carbon isotope ratios ${ }^{\mathrm{a}}$.

\begin{tabular}{lrrrrr}
\hline Range for $\delta^{13} \mathrm{C}$ & Benzene & Toluene & Ethylbenzene & $o$-Xylene & $p, m$-Xylene \\
\hline$<\delta^{13} \mathrm{C}_{\text {source }}^{\mathrm{b}}$ & $1(2 \%)$ & 0 & $4(7 \%)$ & $4(9 \%)$ & $4(7 \%)$ \\
$\approx \delta^{13} \mathrm{C}_{\text {source }}^{\mathrm{c}}$ & $10(23 \%)$ & $32(44 \%)$ & $14(24 \%)$ & $5(11 \%)$ & $15(27 \%)$ \\
$>\delta \delta^{13} \mathrm{C}_{\text {source but }<\delta^{13} \mathrm{C}_{\text {global }}^{\mathrm{d}}}$ & $28(64 \%)$ & $15(21 \%)$ & $4(7 \%)$ & $6(14 \%)$ & $4(7 \%)$ \\
$\approx \delta^{13} \mathrm{C}_{\text {steady state }}^{\mathrm{e}}$ & $2(4 \%)$ & $23(31 \%)$ & $19(33 \%)$ & $17(39 \%)$ & $21(38 \%)$ \\
$>\delta \delta^{13} \mathrm{C}_{\text {steady state }}^{\mathrm{f}}$ & $3(7 \%)$ & $3(4 \%)$ & $17(29 \%)$ & $12(27 \%)$ & $12(21 \%)$ \\
\hline Total & 44 & 73 & 58 & 44 & 56 \\
\hline
\end{tabular}

a The value in parenthesis gives the percentage of observation. The confidence intervals used to determine the $\delta^{13} \mathrm{C}$ ranges were calculated from measurement error, uncertainty of $\delta^{13} \mathrm{C}$ of emissions, and uncertainty of $\varepsilon_{\mathrm{OH}} \cdot{ }^{\mathrm{b}}$ Number of $\delta^{13} \mathrm{C}$ measurements below the $95 \%$ confidence limit of $\delta^{13} \mathrm{C}$ of emissions. ${ }^{\mathrm{c}}$ Number of $\delta^{13} \mathrm{C}$ measurements within the $95 \%$ confidence limit of $\delta^{13} \mathrm{C}$ of emissions. ${ }^{\mathrm{d}}$ Number of $\delta^{13} \mathrm{C}$ measurements above the $95 \%$ confidence limit of $\delta^{13} \mathrm{C}$ of emissions but below the $95 \%$ confidence limit of $\delta^{13} \mathrm{C}$ calculated for steady state between emissions and loss. ${ }^{\mathrm{e}}$ Number of $\delta^{13} \mathrm{C}$ measurements within the $95 \%$ confidence limits of $\delta^{13} \mathrm{C}$ calculated for steady state between emissions and loss. ${ }^{\mathrm{f}}$ Number of $\delta^{13} \mathrm{C}$ measurements above the $95 \%$ confidence limit of $\delta^{13} \mathrm{C}$ calculated for steady state between emissions and loss.

Table 12. Comparison of slopes calculated from Eq. (4) based on the assumption that different VOC have identical $\int[\mathrm{OH}] \mathrm{d} t$ (above diagonal) with slopes determined from linear regression of the observations (below diagonal).

\begin{tabular}{lrrrrr}
\hline & Benzene & Toluene & Ethylbenzene & $o$-Xylene & $p, m$-Xylene \\
\hline Benzene & & 3.29 & 3.18 & 6.07 & 6.08 \\
Toluene & NA $^{\mathrm{a}}$ & & 0.97 & 3.15 & 1.85 \\
Ethylbenzene & NA & $0.96(0.17)^{\mathrm{b}}$ & & 3.26 & 1.91 \\
$o$-Xylene & NA & $0.85(0.18)^{\mathrm{b}}$ & $0.89(0.07)^{\mathrm{b}}$ & & 0.59 \\
$p, m$-Xylene & NA & $0.95(0.18)^{\mathrm{b}}$ & $1.0(0.03)^{\mathrm{b}}$ & $0.93(0.07)^{\mathrm{b}}$ & \\
\hline
\end{tabular}

${ }^{a}$ Not available, no correlation found. ${ }^{b}$ Standard error in parenthesis.

Table 13. Overview of $\int[\mathrm{OH}] \mathrm{d} t^{\mathrm{a}}$ of light aromatic VOC calculated from their stable carbon isotope ratios.

\begin{tabular}{lrrrrrr}
\hline Compound & Mean $^{\mathrm{b}}$ & Median $^{\mathrm{c}}$ & 90th percentile & 75th percentile & 25th percentile & 10th percentile \\
\hline Benzene & $31(5)$ & $21(14)$ & 76 & 49 & 11 & -4.1 \\
Toluene & $8.5(1.1)$ & $5.7(8)$ & 21 & 12 & 1.6 & 0.61 \\
Ethylbenzene & $12.1(1.7)$ & $14(5.7)$ & 29 & 20 & 2.3 & -2.8 \\
$o$-Xylene & $6.8(0.9)$ & $6.8(2.6)$ & 15 & 10 & 1.9 & -1.5 \\
$p, m$-Xylene & $3.4(0.6)$ & $3.6(2.4)$ & 8.7 & 6.5 & 0.5 & -1.0 \\
\hline
\end{tabular}

a $\int[\mathrm{OH}] \mathrm{d} t$ in $10^{10} \mathrm{~s}$ molecules $\mathrm{cm}^{-3} \cdot{ }^{\mathrm{b}}$ Standard error of mean in parenthesis. ${ }^{\mathrm{c}} 95 \%$ confidence interval in parenthesis.

ences in $\int[\mathrm{OH}] \mathrm{d} t$ for $\mathrm{VOC}$ with different reactivity is similar to the results of a comparison of the ages of ethane and nbutane derived from carbon isotope ratios reported by Saito et al. (2002) for the western North Pacific. They report that the age of ethane in most cases is approximately an order of magnitude larger than the age of $n$-butane, which is similar to the $\int[\mathrm{OH}] \mathrm{d} t$-reactivity dependence in Fig. 6, although the range of VOC reactivity covered in this paper does not include the low reactivity of ethane.

The dependence of the $\int[\mathrm{OH}] \mathrm{d} t$ on VOC reactivity is also seen for individual samples. In Fig. 7 the $\int[\mathrm{OH}] \mathrm{d} t$ of different VOC are compared with $\int[\mathrm{OH}] \mathrm{d} t$ determined for $p, m$ xylene, the most reactive VOC. Since the $\int[\mathrm{OH}] \mathrm{d} t$ is a linear function of the carbon isotope ratios (Eq. 3) it is not surprising that the comparison showed strong correlations between the values for $\int[\mathrm{OH}] \mathrm{d} t$ of the $\mathrm{C}_{2}$-alkylbenzenes and no significant linear correlation between the $\int[\mathrm{OH}] \mathrm{d} t$ of benzene and $\int[\mathrm{OH}] \mathrm{d} t$ of $p, m$-xylene. With the exception of four data points for $\int[\mathrm{OH}] \mathrm{d} t$ of toluene the values for $\int[\mathrm{OH}] \mathrm{d} t$ of less reactive $\mathrm{VOC}$ were consistently higher than those for $p, m$ xylene, the most reactive of the studied VOC.

The systematic dependence of $\int[\mathrm{OH}] \mathrm{d} t$ on VOC reactivity can be explained by mixing of air masses that have been subject to different extents of photochemical processing. During photochemical aging VOC of high reactivity will be removed at a faster rate than VOC of low reactivity. Consequently the 

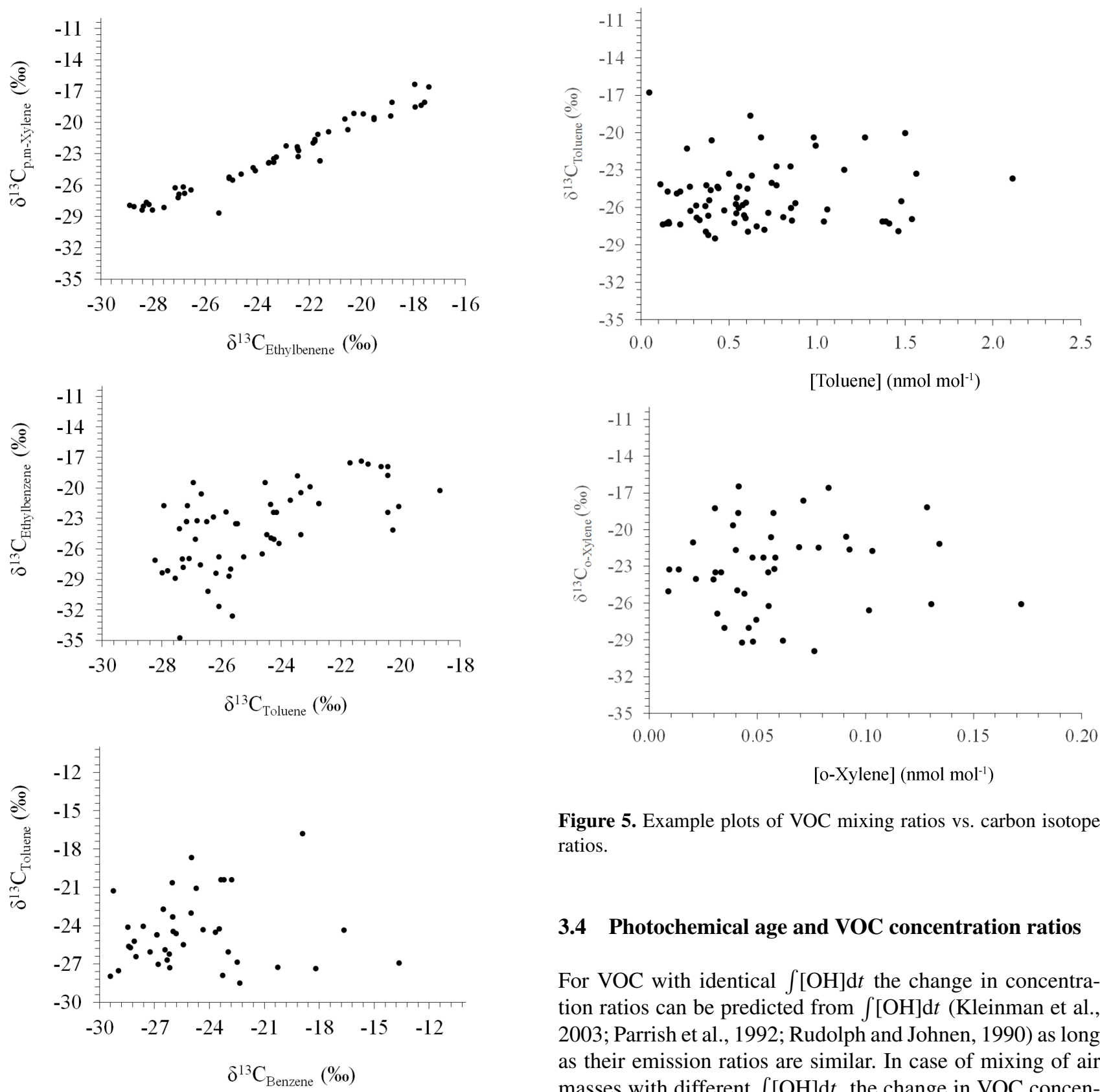

Figure 4. Example plots for the dependence between carbon isotope ratios for different VOC pairs.

relative contribution to VOC of low reactivity compared to VOC of high reactivity increases with increased photochemical processing and mixing of air masses that have been subject to different degrees of photochemical processing will result in average $\int[\mathrm{OH}] \mathrm{d} t$ values that decrease with increasing VOC reactivity.

Figure 5. Example plots of VOC mixing ratios vs. carbon isotope ratios.

\subsection{Photochemical age and VOC concentration ratios}

For VOC with identical $\int[\mathrm{OH}] \mathrm{d} t$ the change in concentration ratios can be predicted from $\int[\mathrm{OH}] \mathrm{d} t$ (Kleinman et al., 2003; Parrish et al., 1992; Rudolph and Johnen, 1990) as long as their emission ratios are similar. In case of mixing of air masses with different $\int[\mathrm{OH}] \mathrm{d} t$, the change in VOC concentration ratios depends on the relative contributions from the different air masses and therefore is difficult to predict. The possibility of deriving $\int[\mathrm{OH}] \mathrm{d} t$ for $\mathrm{VOC}$ from their carbon isotope ratios allows study of the dependence between VOC ratios and $\int[\mathrm{OH}] \mathrm{d} t$ of the individual compound. The only condition for this is a narrow range of carbon isotope ratios for the emissions of the studied VOC.

Figure 8 shows some examples for the dependence between VOC concentration ratios and $\int[\mathrm{OH}] \mathrm{d} t$ of $o$-xylene and toluene. The ratios exhibit substantial scatter, especially for ratios relative to benzene or toluene. Overall there is no clear dependence between $\int[\mathrm{OH}] \mathrm{d} t$ and VOC ratios. For many VOC pairs the ratios show substantial deviations from the dependence between $\int[\mathrm{OH}] \mathrm{d} t$ and concentration ratios 


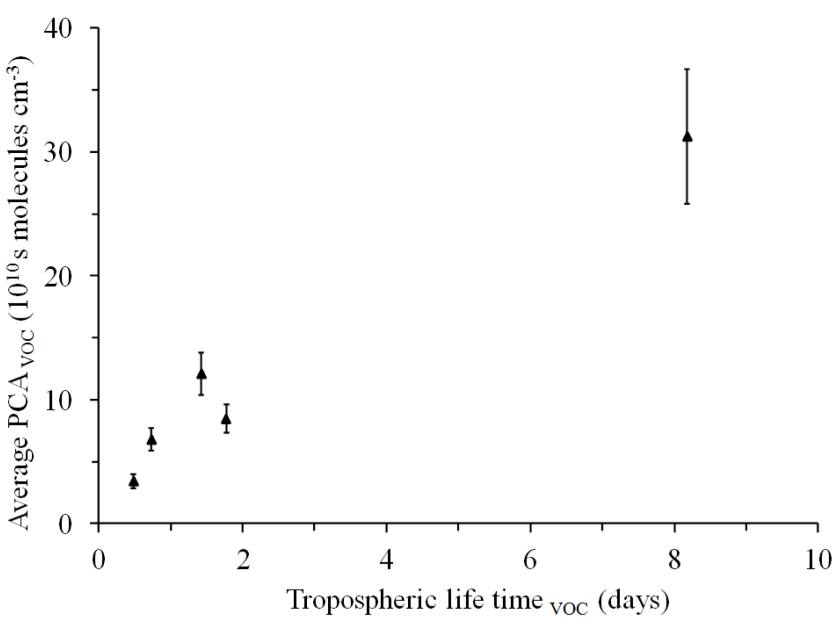

Figure 6. Dependence between average $\int[\mathrm{OH}] \mathrm{d} t$ (photochemical age, PCA) and photochemical lifetime for light aromatic VOC. The average tropospheric lifetime was calculated using the rate constants given in Table 10 and an average tropospheric concentration of $1.16 \times 10^{6} \mathrm{OH}$-radicals cm ${ }^{-3}$ (Spivakovsky et al., 2000). Vertical error bars are the standard error of the mean.

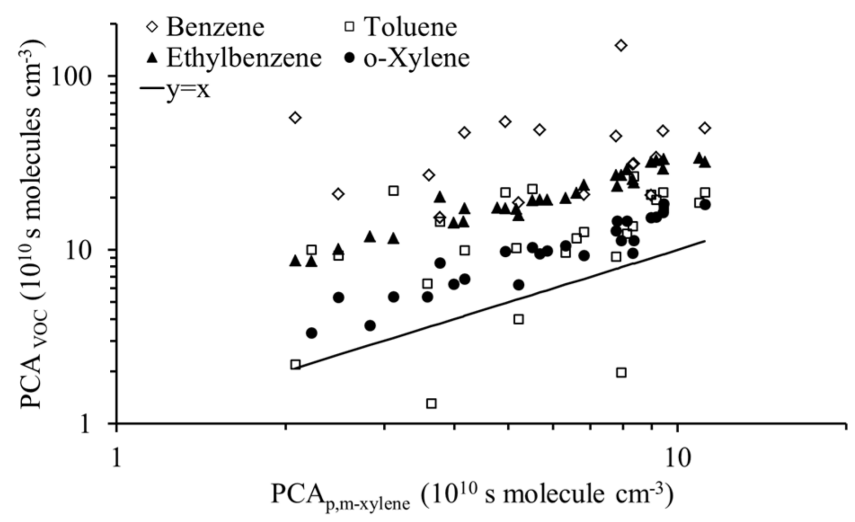

Figure 7. Dependence between the $\int[\mathrm{OH}] \mathrm{d} t$ (PCA) of different VOC and the $\int[\mathrm{OH}] \mathrm{d} t$ (PCA) of $p, m$-xylene. Only data with $\int[\mathrm{OH}] \mathrm{d} t$ larger than 0 at a $95 \%$ confidence limit are shown.

predicted for identical values for average $\int[\mathrm{OH}] \mathrm{d} t$. However, for VOC pairs with similar reactivity or low reactivity for both VOC prediction and observation agree. This suggests that, similar to the dependence between VOC concentrations and carbon isotope ratios (Fig. 5), mixing of air masses with different VOC concentration ratios plays a major role in determining $\mathrm{VOC}$ ratios.

A change in VOC concentration ratios may be caused by varying impact from emission sources with different emission ratios or different $\int[\mathrm{OH}] \mathrm{d} t$. With increasing photochemical age the concentrations of a more reactive VOC will decrease faster than the concentration of a less reactive VOC. In case of mixing air masses containing VOC with different $\int[\mathrm{OH}] \mathrm{d} t$ the relation predicted by the hydrocarbon clock concept is no longer applicable, but qualitatively the ratios
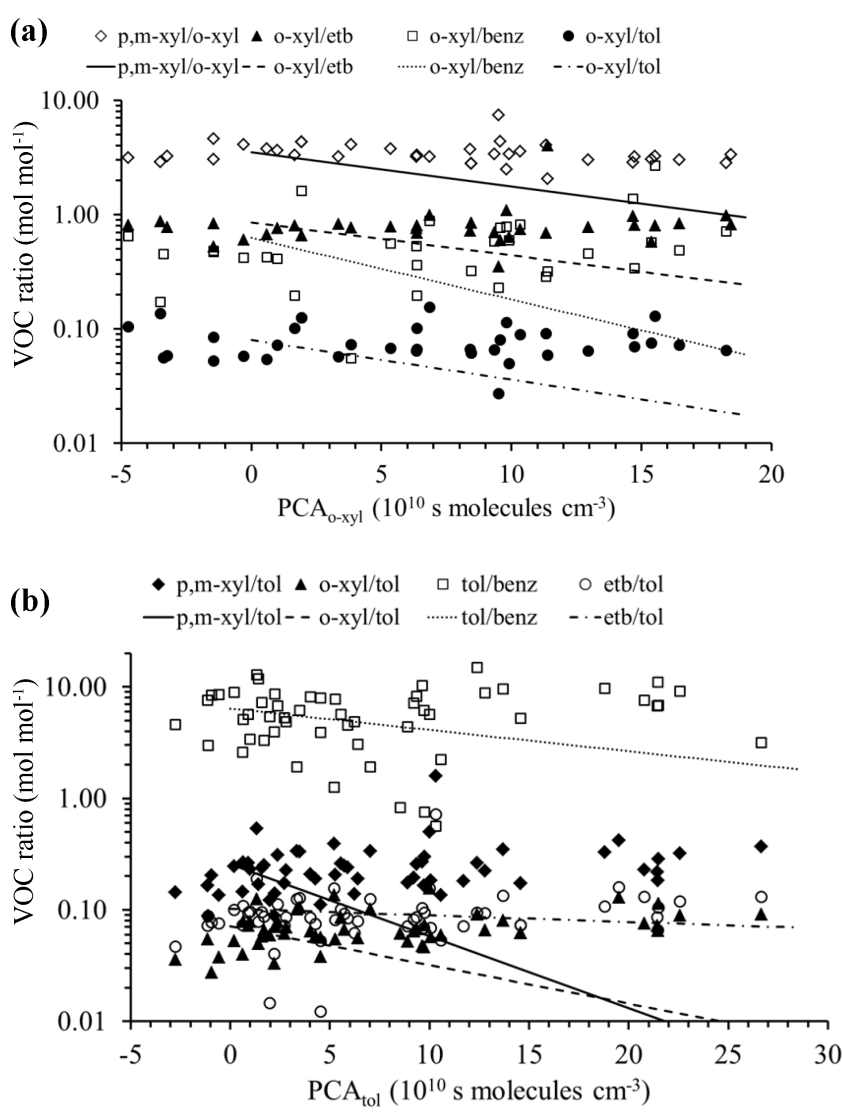

Figure 8. Plot of VOC concentration ratios vs. $\int[\mathrm{OH}] \mathrm{d} t(\mathrm{PCA}) \mathrm{de}-$ termined from carbon isotope ratios. The lines show the change in carbon isotope ratios predicted for identical $\int[\mathrm{OH}] \mathrm{d} t$ of the different VOC.

for concentrations of more reactive VOC over those of less reactive VOC will still decrease with increasing $\int[\mathrm{OH}] \mathrm{d} t$.

Figure 9 shows the relative change in the ratios for the concentration of different VOC over the concentration of benzene averaged for four intervals of $\int[\mathrm{OH}] \mathrm{d} t$ derived from the $p, m$-xylene carbon isotope ratio. Also shown is the relative change in $\int[\mathrm{OH}] \mathrm{d} t$ of benzene for the same intervals. Although the averages have substantial uncertainties, there is evidence for a systematic dependence. For the $\mathrm{C}_{2}$ alkylbenzenes the difference between the lowest and highest ratios is significant at the $90 \%$ confidence level ( $t$ test). Furthermore, it is unlikely that the observation of similar trends for all ratios is a coincidence. Most importantly, the observations are incompatible with the expected change of VOC concentration ratios with increasing $\int[\mathrm{OH}] \mathrm{d} t$. Benzene is by far the least reactive of these VOC; consequently photochemical processing is expected to decrease the alkylbenzene over benzene concentration ratios, which is not observed.

Figure 10 shows the relative difference between the averages for all VOC concentration ratios and the average concentration ratios for VOC without significant depletion of ${ }^{13} \mathrm{C}$ relative to the isotope ratio of emissions. The separation 


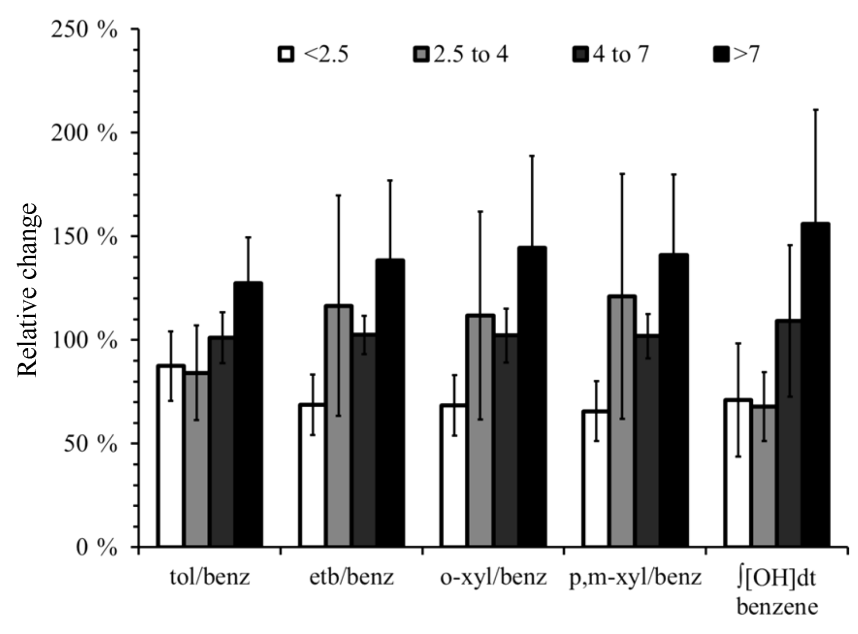

Figure 9. Relative change of VOC concentration ratios and $\int[\mathrm{OH}] \mathrm{d} t(\mathrm{PCA})$ of benzene for different ranges of $\int[\mathrm{OH}] \mathrm{d} t$ (in units of $10^{10} \mathrm{~s}$ molecules $\mathrm{cm}^{-3}$ ) derived from the carbon isotope ratio of $p, m$-xylene. The bars represent the ratio of the mean concentration ratios for the chosen interval of $\int[\mathrm{OH}] \mathrm{d} t$ over the average for all concentration ratios. The error bars are the relative standard errors of the mean. The range of $\int[\mathrm{OH}] \mathrm{d} t$ for the lowest $\int[\mathrm{OH}] \mathrm{d} t$ bin was chosen to include all $\int[\mathrm{OH}] \mathrm{d} t$, which are not significantly larger than 0. (95\% confidence limit). The other ranges were chosen to include between 8 and 12 data points in each bin.

between these two groups is based on the $95 \%$ confidence limit calculated from measurement error and uncertainty of $\delta^{13} \mathrm{C}$ of emissions (Table 10). For comparison the change in ratios predicted from the average $\int[\mathrm{OH}] \mathrm{d} t$ of the $\mathrm{VOC}$ in Table 13 is included in Fig. 10. For $\mathrm{C}_{2}$-alkylbenzenes the predicted and observed changes in concentration ratios agree within their uncertainties, although for the $o$-xylene over ethylbenzene concentration ratio the high uncertainty does not allow a meaningful comparison. However, VOC concentration ratios relative to benzene or toluene show a substantial difference between prediction and observation. Moreover, for concentration ratios relative to benzene, the samples with negligible photochemical processing have ratios lower than the average, which can only be explained by impact of sources with different VOC emission ratios. Specifically, it can be concluded that sources directly impacting the sampling location on average have lower emission ratios relative to benzene than emissions from sources located at a distance allowing for photochemical aging of the VOC. This demonstrates that in this case the differences in emission ratios are larger than the impact of photochemical aging.

Based on the location of the sampling site, traffic-related emissions are expected to have a major impact on VOC concentrations. Other potentially important sources are emissions from industrial facilities. In Table 14 VOC emission ratios for transportation-related emissions from literature and industrial facilities in Ontario and the Toronto region reported by the National Pollutant Release Inventory (NPRI)

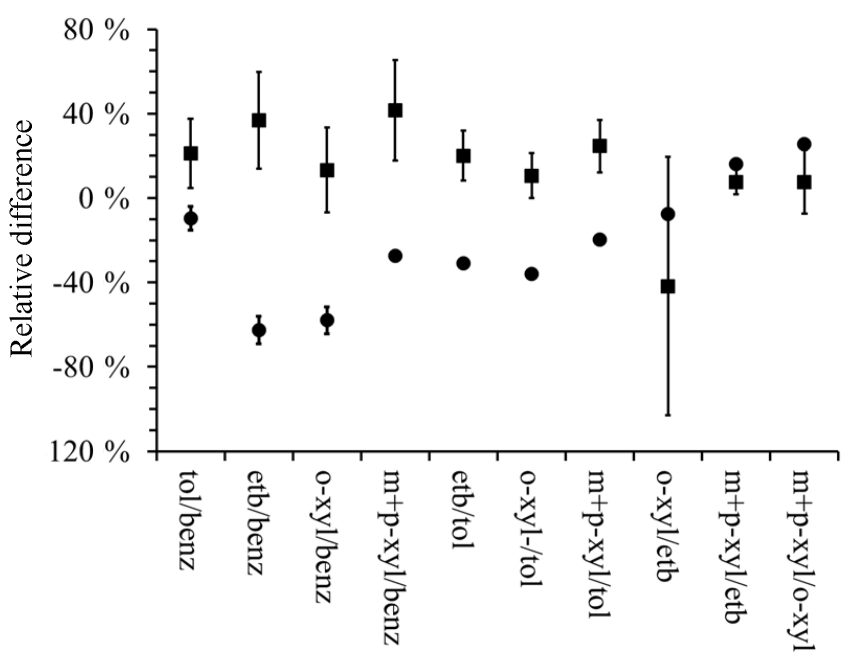

Figure 10. Relative difference between the average of all VOC concentration ratios $\left(\mathrm{mol} \mathrm{mol}^{-1}\right)$ and the average VOC concentration ratios for VOC with carbon isotope ratios that are not higher than the carbon isotope ratios of emissions (95\% confidence limit) (squares). The circles show the relative change expected for a uniform $\int[\mathrm{OH}] \mathrm{d} t$ calculated from the average $\int[\mathrm{OH}] \mathrm{d} t$ of all observations (Table 13). The error bars show the standard error calculated from error propagation. For data points with error bars smaller than the size of the data point, no error bars are shown.

are compared with the average ratios for our measurements. Although VOC concentration ratios in vehicular emissions cover a range of nearly a factor of 2 , the observed average ratios relative to benzene are consistently at the upper end or above this range but close to emission ratios for industrial facilities in Ontario. Since emission ratios relative to benzene for industrial facilities in the Toronto area are much higher than the average for Ontario (Table 14), differences in emission ratios from industrial facilities between Toronto and the rest of Ontario can be ruled out as an explanation for the lower concentration ratios relative to benzene for samples with little photochemical processing. In contrast to the concentration ratios relative to benzene, due to the similarity in emission ratios for industrial facilities and traffic (Table 14) and the possible change of these ratios due to photochemical processing, it is difficult to extract information about contributions from these two source types from concentration ratios for alkylbenzenes without additional information.

Most of the major sources of light aromatic VOC in Ontario are located southwest and west of the sampling site (Fig. 11). Therefore insight into the impact of emissions from industrial facilities on concentration ratios and carbon isotope ratios can be gained by filtering the samples based on predominant wind direction during sampling. In Table 15 the average VOC carbon isotope ratios for the two wind sectors are compared. With the exception of toluene the average carbon isotope ratios for samples collected under the influence of airflow from north or east are heavier than in samples with 
Table 14. Comparison of observed VOC concentration ratios $\left(\mathrm{mol} \mathrm{mol}^{-1}\right)$ with VOC emission ratios for industrial facilities and mobile transportation.

\begin{tabular}{|c|c|c|c|c|c|c|}
\hline $\begin{array}{l}\text { VOC concentration } \\
\text { ratios }\end{array}$ & $\begin{array}{r}\text { Facilities in } \\
\text { Ontario }^{\mathrm{a}}\end{array}$ & $\begin{array}{c}\text { Facilities in } \\
\text { Toronto }^{\mathrm{a}}\end{array}$ & $\begin{array}{l}\text { Gasoline } \\
\text { engines }^{b}\end{array}$ & $\begin{array}{r}\text { Traffic in } \\
\text { Sarnia }^{c}\end{array}$ & $\begin{array}{l}\text { Traffic in eight } \\
\text { European cities }\end{array}$ & $\begin{array}{r}\text { Average of all } \\
\text { observations }\end{array}$ \\
\hline Toluene / benzene & 6.2 & 120 & $2.6 \pm 1.9$ & 3.6 & $2.0 \pm 0.4$ & $6.6 \pm 0.56$ \\
\hline Ethylbenzene / benzene & 0.68 & 13 & $0.20 \pm 0.19$ & 0.57 & $0.38 \pm 0.08$ & $0.69 \pm 0.083$ \\
\hline$\sum$ Xylenes / benzene & 5.3 & 114 & $0.65 \pm 0.50$ & 2.3 & $1.6 \pm 0.4$ & $2.3 \pm 0.17$ \\
\hline$\sum$ Xylenes / toluene & 0.86 & 0.96 & $0.34 \pm 0.28$ & 0.63 & $0.81 \pm 0.2$ & $0.35 \pm 0.019$ \\
\hline$\sum$ Xylenes / ethylbenzene & 7.9 & 8.6 & $4.0 \pm 1.3$ & 4.1 & $4.1 \pm 0.5$ & $3.5 \pm 0.096$ \\
\hline
\end{tabular}

a Calculated from emissions reported by the National Pollution Release Inventory (NPRI) for 2009 and 2010. ${ }^{b}$ Average and standard deviation calculated from 16 measurements of the composition of exhaust from gasoline engines using ethanol-free or low-ethanol-fuel, reported by the United States Environmental Protection Agency, Speciate Data Base (2016). ${ }^{c}$ Calculated from average ratios reported by Miller et al. (2011) for ambient observations dominated by traffic-related emissions in Sarnia (Southern Ontario, Canada). ${ }^{\mathrm{d}}$ Calculated from mixing ratios reported by Monod et al. (2001) for observations dominated by traffic-related emissions in eight major cities in Europe.

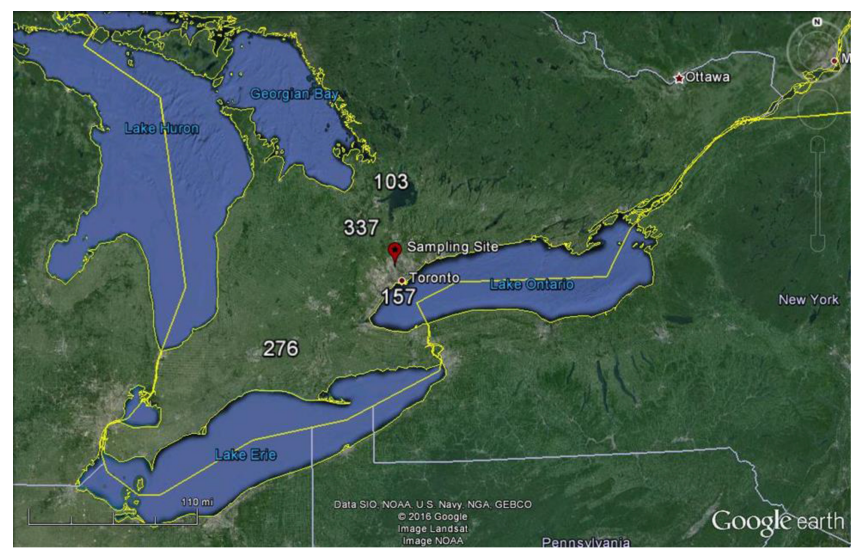

Figure 11. Location of facilities in Southern Ontario with significant emissions of xylenes. The numbers represent the annual emissions in $t_{\text {year }}{ }^{-1}$. Emission data were taken from the National Pollutant Release Inventory (NPRI). Only sources contributing at least $5 \%$ to the total emissions are shown. Also shown is the location of the sampling site. The map was produced using Google Earth $\left({ }^{\circledR}\right.$ 2015).

wind from the southern or western sectors. For benzene this difference is statistically significant at the $98 \%$ level ( $t$ test) and for the $\mathrm{C}_{2}$-benzenes at a $>90 \%$ level. This is consistent with the existence of larger sources of aromatic VOC in the $\mathrm{S}+\mathrm{W}$ sector compared to the $\mathrm{N}+\mathrm{E}$ sector (Fig. 11). The absence of a statistically significant difference in isotope ratios for toluene is most likely due to the existence of a nearby major industrial source of toluene east of the sampling site (Fig. 12).

Based on the difference in carbon isotope ratios between samples for the two wind sectors it is expected that there also will be differences in concentration ratios. In Table 15 average VOC concentration ratios for samples dominated by southerly or westerly airflow are compared with ratios for samples with winds from either north or east. For ratios relative to benzene, substantial differences between the two wind

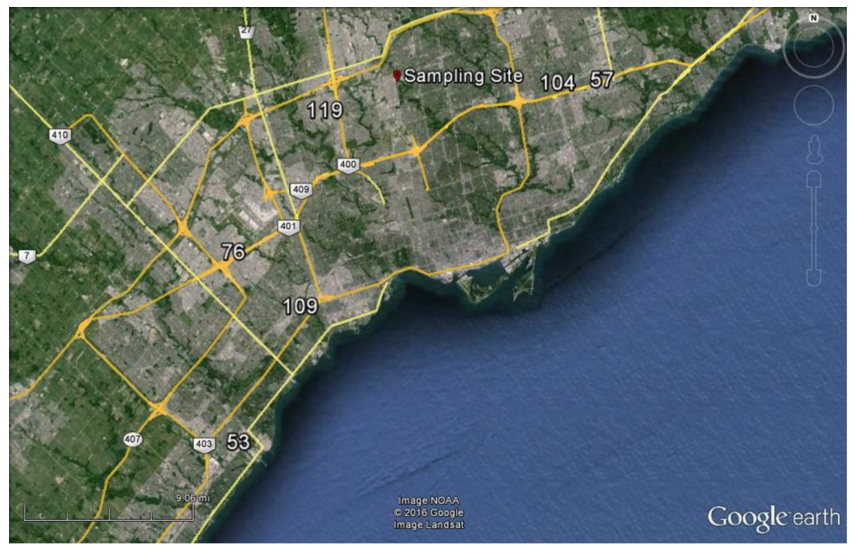

Figure 12. Location of facilities in Toronto with significant emissions of toluene. The numbers represent the annual emissions in t year $^{-1}$. Emission data were taken from the National Pollutant Release Inventory (NPRI). Only sources contributing at least $5 \%$ to the total emissions are shown. Also shown is the location of the sampling site. The map was produced using Google Earth $\left({ }^{\circledR} 2015\right)$.

sectors are found. For the $\mathrm{C}_{2}$-alkylbenzenes the difference is statistically significant at $>95 \%$ ( $t$ test) and for toluene at the $89 \%$ level. However, for concentration ratios between alkylbenzenes no statistically significant differences can be seen. The lower concentration ratios relative to benzene in the $\mathrm{N}+\mathrm{E}$ samples can therefore be explained either by impact of aged air which is, relative to benzene, depleted in the more reactive alkylbenzenes due to photochemical processing or lower emissions of alkylbenzenes from industrial facilities in the $\mathrm{N}+\mathrm{E}$ sector.

VOC carbon isotope ratios can be used to test which of these two factors dominates. Using the carbon isotope ratio of $p, m$-xylene the $\mathrm{N}+\mathrm{E}$ sector samples are separated into two groups of samples with different values for $\int[\mathrm{OH}] \mathrm{d} t$. The separation into two groups is based on $\int[\mathrm{OH}] \mathrm{d} t$ of $p, m$-xylene being larger than 0 at the $99 \%$ confidence limit. The confidence limit was calculated from the uncer- 
Table 15. Comparison of observed VOC concentration ratios $\left(\mathrm{mol} \mathrm{mol}^{-1}\right)$ for different dominant wind directions and different $\int[\mathrm{OH}] \mathrm{d} t$.

\begin{tabular}{lrrrr}
\hline VOC concentration ratios & $\mathrm{S}+\mathrm{W}^{\mathrm{a}}$ & $\mathrm{N}+\mathrm{E}^{\mathrm{b}}$ & $\mathrm{N}+\mathrm{E} \mathrm{recent}^{\mathrm{c}}$ & $\mathrm{N}+\mathrm{E}_{\text {aged }}$ \\
\hline Toluene / benzene & $8.2 \pm 1.5$ & $6.1 \pm 0.90$ & $4.9 \pm 2.2$ & $7.7 \pm 1.6$ \\
Ethylbenzene / benzene & $1.0 \pm 0.2$ & $0.61 \pm 0.10$ & $0.37 \pm 0.11$ & $0.82 \pm 0.16$ \\
$o$-Xylene / benzene & $0.76 \pm 0.17$ & $0.44 \pm 0.09$ & $0.24 \pm 0.06$ & $0.68 \pm 0.15$ \\
$p, m$-Xylene / benzene & $2.8 \pm 0.67$ & $1.5 \pm 0.27$ & $0.81 \pm 0.22$ & $2.2 \pm 0.44$ \\
Ethylbenzene / toluene & $0.11 \pm 0.01$ & $0.13 \pm 0.04$ & $0.074 \pm 0.012$ & $0.17 \pm 0.074$ \\
$o$-Xylene / toluene & $0.084 \pm 0.012$ & $0.069 \pm 0.008$ & $0.048 \pm 0.012$ & $0.084 \pm 0.014$ \\
$p, m$-Xylene / toluene & $0.29 \pm 0.039$ & $0.029 \pm 0.078$ & $0.16 \pm 0.03$ & $0.42 \pm 0.16$ \\
$o$-Xylene / ethylbenzene & $0.93 \pm 0.24$ & $0.94 \pm 0.23$ & $0.66 \pm 0.07$ & $1.2 \pm 0.51$ \\
$p, m$-Xylene / ethylbenzene & $2.5 \pm 0.14$ & $2.7 \pm 0.37$ & $2.2 \pm 0.15$ & $3.3 \pm 0.80$ \\
$p, m$-Xylene / $o$-xylene & $3.6 \pm 0.27$ & $3.3 \pm 0.23$ & $3.4 \pm 0.20$ & $3.1 \pm 0.28$ \\
$\sum$ Xylenes / benzene & $3.3 \pm 0.81$ & $1.8 \pm 0.34$ & $1.0 \pm 0.29$ & $2.7 \pm 0.55$ \\
$\sum$ Xylenes / toluene & $0.35 \pm 0.051$ & $0.34 \pm 0.076$ & $0.21 \pm 0.042$ & $0.49 \pm 0.15$ \\
$\sum$ Xylenes / ethylbenzene & $3.3 \pm 0.17$ & $3.5 \pm 0.34$ & $2.8 \pm 0.21$ & $4.1 \pm 1.1$ \\
\hline
\end{tabular}

a Average ratio for data with winds dominantly from southern or western sectors. Only data points for which the wind direction was within $\pm 45^{\circ}$ of the dominant wind direction during at least $80 \%$ of the sampling time are included. The number of data points is between 14 and 20 . The uncertainty stated is the standard error of the mean. ${ }^{b}$ Average ratios for data with winds dominantly from northern or eastern sectors are included. Only data points for which the wind direction was within $\pm 45^{\circ}$ of the dominant wind direction during at least $80 \%$ of the sampling time are included. The number of data points is between 15 and 20 . The uncertainty stated is the standard error of the mean. ${ }^{\mathrm{c}}$ Data for the $\mathrm{N}+\mathrm{E}$ sector filtered based on $\int[\mathrm{OH}] \mathrm{d} t$ determined from the $\mathrm{p}, \mathrm{m}$ - xylene carbon isotope ratio. Aged refers to samples with $\int[\mathrm{OH}] \mathrm{d} t>0$ at the $99 \%$ confidence limit. The confidence limit was calculated from the uncertainty of the isotope ratio of emissions, the measurement uncertainty and the uncertainty of the KIE. Recent represents samples with $\int[\mathrm{OH}] \mathrm{d} t$ below this limit. The values given are the average ratios and the standard error of the mean. The number of data points for recent is five; for aged there are between seven and nine values.

tainty of the isotope ratio of emissions, the measurement uncertainty and the uncertainty of the KIE. This $\int[\mathrm{OH}] \mathrm{d} t$ is $3 \times 10^{10} \mathrm{OH}$-radicals $\mathrm{cm}^{-3} \mathrm{~s}$, which corresponds to approximately $8 \mathrm{~h}$ for an average $\mathrm{OH}$-radical concentration of $10^{6} \mathrm{~cm}^{-3}$. The average concentration ratios for these two groups are included in Table 15 . The average $\int[\mathrm{OH}] \mathrm{d} t$ of $p, m$-xylene for samples dominated by recent emissions of $p, m$-xylene is $2.3 \times 10^{9} \mathrm{OH}$-radicals $\mathrm{cm}^{-3} \mathrm{~s}$, corresponding to $0.6 \mathrm{~h}$ for an average $\mathrm{OH}$-radical concentration of $10^{6} \mathrm{~cm}^{-3}$. However, it should be noted that, due to the uncertainty in the isotope ratio of $p, m$-xylene emissions, this average value has an uncertainty of approximately $1.3 \times 10^{10} \mathrm{OH}-$ radicals $\mathrm{cm}^{-3} \mathrm{~s}$, corresponding to nearly $4 \mathrm{~h}$ for an average $\mathrm{OH}$-radical concentration of $10^{6} \mathrm{~cm}^{-3}$. For samples dominated by aged $p, m$-xylene the average $\int[\mathrm{OH}] \mathrm{d} t$ is $7.4 \times$ $10^{10} \mathrm{OH}$-radicals $\mathrm{cm}^{-3} \mathrm{~s}$, corresponding to $21 \mathrm{~h}$ for an average $\mathrm{OH}$-radical concentration of $10^{6} \mathrm{~cm}^{-3}$.

In contrast to the expected decrease in the concentration ratios for more reactive VOC over less reactive VOC with increasing $\int[\mathrm{OH}] \mathrm{d} t$, the average ratios are always higher for the aged samples. Although the difference is statistically significant at a $>90 \%$ level for only six of the concentration ratios, this finding rules out photochemical processing as main reason for the observed changes in VOC concentration ratios. For this set of observations differences in $\int[\mathrm{OH}] \mathrm{d} t$ derived from carbon isotope ratios most likely reflect differences in the footprint area that impacts VOC concentration ratios. Samples with low values for $\int[\mathrm{OH}] \mathrm{d} t$ represent the impact of nearby sources, most likely traffic-related emis- sions, consistent with concentration ratios that are close to the typical traffic-dominated VOC ratios (Table 14).

The concentration ratio of $p, m$-xylene over ethylbenzene has been used as an indicator of photochemical processing (Miller et al., 2012; Monod, 2001). It has been reported that the ratio of $p, m$-xylene to ethylbenzene emissions is nearly constant for different sources (i.e., exhaust, petrochemical activities, solvent use) and varies from 3.5 to 4.0 (Nelson and Quigley, 1983). Since photochemical removal is approximately 3 times faster for $p, m$-xylene than for ethylbenzene (Table 6), it has been suggested that any value of this ratio lower than 3.5 is a good indicator of photochemical ageing (Nelson and Quigley, 1983; Miller et al., 2012; Monod, 2001; Civan et al., 2015). This is in contrast to the higher concentration ratio of $p, m$-xylene to ethylbenzene observed in samples with photo-chemically aged $p, m$-xylene for the $\mathrm{N}+\mathrm{E}$ sector compared to samples dominated by recent emission of $p, m$-xylene (Table 15). Although the observed relative increase in concentration ratios of $50 \%$ has an uncertainty of $40 \%$ and is statistically not significant ( $t$ test), it is inconsistent with the decrease by approximately $60 \%$ which is expected from the difference in the average $\int[\mathrm{OH}] \mathrm{d} t$ for these two data sets. This can be explained by the difference in xylene over ethylbenzene emission ratios between trafficrelated emissions and industrial facility emissions (Table 14). Samples with low values for the average $\int[\mathrm{OH}] \mathrm{d} t$ for $p, m$ xylene will be dominated by emissions from nearby sources, most likely traffic, while for samples with higher $\int[\mathrm{OH}] \mathrm{d} t$ for $p, m$-xylene the footprint area will be much larger and industrial emissions will play a more significant role. 


\section{Conclusions}

Measurement of carbon isotope ratios of ambient VOC can be used to obtain detailed insight into origin and sources of VOC. This is especially important in cases where different source types impact ambient VOC levels and the source location alone does not allow the identification of the dominant source type. In such cases the use of VOC concentration ratios can result in incorrect estimates of photochemical processing. Moreover, the comparison of $\int[\mathrm{OH}] \mathrm{d} t$ derived from carbon isotope ratios of VOC demonstrates that in the case of mixing of air masses with differences in $\int[\mathrm{OH}] \mathrm{d} t$ the average $\int[\mathrm{OH}] \mathrm{d} t$ for VOC with different reactivity differs. Typically $\int[\mathrm{OH}] \mathrm{d} t$ for more reactive VOC will be lower than $\int[\mathrm{OH}] \mathrm{d} t$ for less reactive VOC. It can therefore be concluded that in this study the assumption of a uniform $\int[\mathrm{OH}] \mathrm{d} t$ for different VOC is not justified and consequently the use of VOC concentration ratios to determine $\int[\mathrm{OH}] \mathrm{d} t$ would give incorrect results.

The use of carbon isotope ratios or $\int[\mathrm{OH}] \mathrm{d} t$ derived from carbon isotope ratios allows differentiation between samples impacted by emissions from different footprint areas. The comparison of carbon isotope ratios and VOC concentration ratios demonstrates that in this study differences in the emission ratios for different types of VOC sources have a larger impact on ambient VOC concentration ratios than photochemical aging.

For the VOC studied here reaction with the $\mathrm{OH}$ radical is the only relevant loss process in the atmosphere. Although the $\mathrm{OH}$-radical concentration exhibits significant seasonal, diurnal and spatial variability, $\int[\mathrm{OH}] \mathrm{d} t$ derived from isotope ratios also depends on the time between emission of the VOC and observation. Consequently $\int[\mathrm{OH}] \mathrm{d} t$ also contains information on the footprint area which impacts the observation site. VOC have widely different photochemical reactivity; the reactivity of VOC used in our study cover a range of a factor of nearly 20 . Values for average $\int[\mathrm{OH}] \mathrm{d} t$ derived from carbon isotope ratios cover the range from effectively 0 to approximately $8 \times 10^{11} \mathrm{OH}$-radicals $\mathrm{cm}^{-3} \mathrm{~s}$, corresponding to 9 days for an average $\mathrm{OH}$-radical concentration of $10^{6} \mathrm{~cm}^{-3}$. The lower end of useful values for $\int[\mathrm{OH}] \mathrm{d} t$ that can be determined from VOC carbon isotope ratios strongly depends on the uncertainty of the carbon isotope ratio of emissions. Due to the limited number of studies of carbon isotope ratios of VOC emissions, this substantially contributes to uncertainty in isotope-ratio-derived $\int[\mathrm{OH}] \mathrm{d} t$. For the most reactive VOC used in this study the uncertainty in $\int[\mathrm{OH}] \mathrm{d} t$ resulting from uncertainty in the carbon isotope ratio of emissions corresponds to $4 \mathrm{~h}$ at an average $\mathrm{OH}$-radical concentration of $10^{6} \mathrm{~cm}^{-3}$. The uncertainty in $\int[\mathrm{OH}] \mathrm{d} t$ of $p, m$-xylene due to carbon isotope ratio measurement errors corresponds to less than $1.5 \mathrm{~h}$. Therefore more detailed understanding of the carbon isotope ratio of VOC emissions will reduce the lower end of meaningful values for $\int[\mathrm{OH}] \mathrm{d} t$ that can be determined from carbon isotope ratios of atmospheric VOC.
In this study sampling periods of at least several hours, in most cases of 1 day were used. This is useful for determining meaningful averages from a limited set of measurements. However, this does not allow differentiating between changes of $\int[\mathrm{OH}] \mathrm{d} t$ with time during the sampling period and mixing VOC with different $\int[\mathrm{OH}] \mathrm{d} t$ in the atmosphere prior to sampling. Separating the impact of the two processes on the VOC isotope ratio would require VOC isotope ratio measurements in samples collected during short time periods of only a few minutes or less. To our knowledge no such VOC isotope ratio measurements in an urban environment have been published.

The finding of a dependence between average $\int[\mathrm{OH}] \mathrm{d} t$ and VOC reactivity is similar to the finding of a substantial difference in $\int[\mathrm{OH}] \mathrm{d} t$ between ethane and n-butane in a marine environment (Saito et al., 2002) as well as global modeling studies (Thompson et al., 2003; Stein and Rudolph, 2007). However, to our knowledge, apart from this study no data that would allow systematic study of the relation between VOC concentration ratios and carbon isotope ratios in urban areas have been published. It can therefore not be decided to what extent the observed discrepancy between $\int[\mathrm{OH}] \mathrm{d} t$ derived from carbon isotope ratios and changes in VOC concentration ratios is a general problem for determining $\int[\mathrm{OH}] \mathrm{d} t$ from VOC concentration ratios or limited to conditions specific for this or similar data sets.

\section{The Supplement related to this article is available online at doi:10.5194/acp-16-11755-2016-supplement.}

Acknowledgements. The authors would like to thank Darrell Ernst and Wendy Zhang at Environment Canada for technical support in isotope ratio measurements. This research was supported financially by the Natural Sciences and Engineering Research Council of Canada (NSERC) and the Canadian Foundation for Climate and Atmospheric Sciences (CFCAS).

Edited by: J. Kaiser

Reviewed by: two anonymous referees

\section{References}

Alghamdi, M. A. K., Abdelmaksoud, A. S., Harrison, R. M., Hussein, T., Lihavainen, H., Al-Jeelani, H., Goknil, M. H., Shabbaj, I. I., Almehmadi, F. M., Hyvärinen, A.-P., and Hämeri, K.: Seasonal and diurnal variations of BTEX and their potential for ozone formation in the urban background atmosphere of the coastal city Jeddah, Saudi Arabia, Air Qual. Atmos. Health, 7, 467-480, doi:10.1007/s11869-014-0263-x, 2014.

Anderson, R., Huang, L., Iannone, R., Thompson, A., and Rudolph, $\mathrm{J}$.: Carbon kinetic isotope effects in the gas phase reactions of light alkanes and ethene with the $\mathrm{OH}$ radical at $296+/-4 \mathrm{~K}$, 
J. Phys. Chem. A, 108, 11537-11544, doi:10.1021/jp0472008, 2004a.

Anderson, R., Iannone, R., Thompson, A., Rudolph, J., and Huang, L.: Carbon kinetic isotope effects in the gas-phase reactions of aromatic hydrocarbons with the $\mathrm{OH}$ radical at $296+/-4 \mathrm{~K}$, Geophys. Res. Lett., 31, L15108, doi:10.1029/2004g1020089, 2004 b.

Atkinson, R. and Arey, J.: Atmospheric degradation of volatile organic compounds, Chem. Rev., 103, 4605-4638, doi:10.1021/cr0206420, 2003.

Brenninkmeijer, C. A. M., Lowe, D. C., Manning, M. R., Sparks, R. J., and Van Velthoven, P. F. J.: The 13C, 14C, and $18 \mathrm{O}$ isotopic composition of $\mathrm{CO}, \mathrm{CH}_{4}$, and $\mathrm{CO}_{2}$ in the higher southern latitudes lower stratosphere, J. Geophys. Res., 100, 26163-126172, doi:10.1029/95JD02528, 1995.

Civan, M. Y., Elbir, T., Seyfioglu, R., Kuntasal, Ö. O., Bayram, A., Doğan, G., Yurdakul, S., Andiç, Ö., Müezzinoğlu, A., Sofuoglu, S. C., Pekey, H., Pekey, B., Bozlaker, A., Odabasi, M., and Tuncel, G.: Spatial and temporal variations in atmospheric VOCs, $\mathrm{NO}_{2}, \mathrm{SO}_{2}$, and $\mathrm{O}_{3}$ concentrations at a heavily industrialized region in Western Turkey, and assessment of the carcinogenic risk levels of benzene, Atmos. Environ., 103, 102-113, doi:10.1016/j.atmosenv.2014.12.031, 2015.

Craig, H.: The geochemistry of the stable carbon isotopes, Geochim. Cosmochim. Ac., 3, 53-92, doi:10.1016/00167037(53)90001-5, 1953.

Czapiewski, C. V., Czuba, E., Huang, L., Ernst, D., Norman, A. L., Koppmann, R., and Rudolph, J.: Isotopic composition of nonmethane hydrocarbons in emissions from biomass burning, J. Atmos. Chem., 43, 45-60, doi:10.1023/A:1016105030624, 2002.

de Gennaro, G., Dambruoso, P. R., Di Gilio, L., Marzocca, A., and Tutino, M.: Indoor and outdoor volatile organic compounds monitoring in a multi-storey car park, Environ. Eng. Manag. J., 14, 1563-1570, 2015.

Elsner, M., Jochmann, M. A., Hofstetter, T. B., Hunkeler, D., Bernstein, A., Schmidt, T. C., and Schimmelmann, A.: Current challenges in compound-specific stable isotope analysis of environmental organic contaminants, Anal. Bioanal. Chem., 403, 24712491, doi:10.1007/s00216-011-5683-y, 2012.

Finlayson-Pitts, B. J. and Pitts, J. N. J.: Chemistry of the upper and lower atmosphere, Academic Press, San Diego, 2000.

Forstener, H. J., Flagan, R. C., and Seinfeld, J. H.: Secondary organic aerosol from the photooxidation of aromatic hydrocarbons: Molecular composition, Environ. Sci. Technol., 31, 1345-1358, doi:10.1021/es9605376, 1997.

Gensch, I., Kiendler-Scharr, A., and Rudolph, J.: Isotope ratio studies of atmospheric organic compounds: Principles, methods, applications and potential, Int. J. Mass. Spectrom., 365-366, 206221, doi:10.1016/j.ijms.2014.02.004, 2014.

Ghosh, P. and Brand, W. A.: Stable isotope ratio mass spectrometry in global climate change research, Int. J. Mass. Spectrom., 228, 1-33, doi:10.1016/s1387-3806(03)00289-6, 2003.

Giebel, B. M., Swart, P. K., and Riemer, D. D.: $\delta 13 C$ Stable isotope analysis of atmospheric oxygenated volatile organic compounds by gas chromatography-isotope ratio mass spectrometry, Anal. Chem., 82, 6797-6806, doi:10.1021/ac1007442, 2010.

Goldstein, A. and Shaw, S.: Isotopes of volatile organic compounds: an emerging approach for studying atmospheric budgets and chemistry, Chem. Rev., 103, 5025-5048, doi:10.1021/cr0206566, 2003.
Google Earth: ${ }^{\circledR}$ Google Earth, http://www.google.com/earth/, last access: 11 July 2015.

Hagerman, L. M., Aneja, V. P., and Lonneman, W. A.: Characterization of non-methane hydrocarbons in the rural southeast United States, Atmos. Environ., 31, 4017-4038, doi:10.1016/S13522310(97)00223-9, 1997.

Hoque, R. R., Khillare, P. S., Agarwal, T., Shridhar, V., and Balachandran, S.: Spatial and temporal variation of BTEX in the urban atmosphere of Delhi, India, Sci. Total Environ., 392, 30-40, doi:10.1016/j.scitotenv.2007.08.036, 2008.

Irei, S., Huang, L., Collin, F., Zhang, W., Hastie, D., and Rudolph, J.: Flow reactor studies of the stable carbon isotope composition of secondary particulate organic matter generated by OH-radicalinduced reactions of toluene, Atmos. Environ., 40, 5858-5867, doi:10.1016/j.atmosenv.2006.05.001, 2006.

Jang, M. and Kamens, R. M.: Characterization of secondary aerosol from the photooxidation of toluene in the presence of $\mathrm{NO}_{x}$ and 1-propene, Environ. Sci. Technol., 35, 3626-3639, doi:10.1021/es010676+, 2001.

Jobson, B. T., Parrish, D. D., Goldan, P., Kuster, W., Fehsenfeld, F. C., Blake, D. R., Blake, N. J., and Niki, H.: Spatial and temporal variability of nonmethane hydrocarbon mixing ratios and their relation to photochemical lifetime, J. Geophys. Res., 103, 13557-513567, doi:10.1029/97JD01715, 1998.

Jobson, B. T., McKeen, S. A., D. D. Parrish, F., Fehsenfeld, C., Blake, D. R., Goldstein, A. H., Schauffler, S. M., and Elkins, A. J. W.: Trace gas mixing ratio variability versus lifetime in the troposphere and stratosphere: Observations, J. Geophys. Res., 104, 16091-16113, doi:10.1029/1999JD900126, 1999.

Jobson, B. T., Berkowitz, C. M., Kuster, W. C., Goldan, P. D., Williams, E. J., Fesenfeld, F. C., Apel, E. C., Karl, T., Lonneman, W. A., and Riemer, D.: Hydrocarbon source signatures in Houston, Texas: Influence of the petrochemical industry, J. Geophys. Res., 109, D24305, doi:10.1029/2004jd004887, 2004.

Karl, T., Apel, E., Hodzic, A., Riemer, D. D., Blake, D. R., and Wiedinmyer, C.: Emissions of volatile organic compounds inferred from airborne flux measurements over a megacity, Atmos. Chem. Phys., 9, 271-285, doi:10.5194/acp-9-271-2009, 2009.

Kawashima, H. and Murakami, M.: Measurement of the stable carbon isotope ratio of atmospheric volatile organic compounds using chromatography, combustion, and isotope ratio mass spectrometry coupled with thermal desorption, Atmos. Environ., 89, 140-147, doi:10.1016/j.atmosenv.2014.02.033, 2014.

Kaye, J. A.: Mechanisms and observations for isotope fractionation of molecular species in planetary atmospheres, Rev. Geophys., 25, 1609-1658, doi:10.1029/RG025i008p01609, 1987.

Kleinman, L. I., Daum, P. H., Lee, L.-N., Nunnermacker, L. J., Springston, S. R., Weinstein-Lloyd, J., Hyde, P., Doskey, P., Rudolph, J., Fast, J., and Berkowitz, C.: Photochemical age determinations in the Phoenix metropolitan area, J. Geophys. Res., 108, 4096, doi:10.1029/2002JD002621, 2003.

Komatsu, D. D., Tsunogai, U., Yamaguchi, J., and Nakagawa, F.: A selective unsaturated hydrocarbon subtraction technique for stable carbon isotopic analysis of atmospheric methyl chloride, methyl bromide, and C2-C5 saturated hydrocarbons using continuous-flow isotope ratio mass spectrometry, Rapid Commun. Mass. Sp., 19, 477-483, doi:10.1002/rcm.1795, 2005.

Kornilova, A., Moukhtar, S., Saccon, M., Huang, L., Zhang, W., and Rudolph, J.: A method for stable carbon isotope ratio and con- 
centration measurements of ambient aromatic hydrocarbons, Atmos. Meas. Tech., 8, 2301-2313, doi:10.5194/amt-8-2301-2015, 2015a.

Kornilova, A., Saccon, M., O’Brien, J. M., Huang, L., and Rudolph, J.: Stable Carbon Isotope Ratios and the Photochemical Age of Atmospheric Volatile Organic Compounds, Atmos.-Ocean, 53, 7-13, doi:10.1080/07055900.2013.822787, 2015b.

Lowe, D. C., Brenninkmeijer, C. A. M., Brailsford, G. W., Lassey, K. R., Gomez, A. J., and Nisbet, E. G.: Concentration and ${ }^{13} \mathrm{C}$ records of atmospheric methane in New Zealand and Antarctica: evidence for changes in methane sources, J. Geophys. Res., 99, 16913-16925, doi:10.1029/94JD00908, 1994.

McKinney, C. R., McCrea, J. M., Epstein, S., Allen, H. A., and Urey, H. C.: Improvements in mass spectrometers for the measurement of small differences in isotope abundance ratios, Rev. Sci. Instrum., 21, 724, doi:10.1063/1.1745698, 1950.

Meier-Augenstein, W.: Applied gas chromatography coupled to isotope ratio mass spectrometry, J. Chrom. A, 842, 351-371, doi:10.1016/S0021-9673(98)01057-7, 1999.

Miller, L., Xu, X., Wheeler, A., Atari, D. O., Grgicak-Mannion, A., and Luginaah, I.: Spatial variability and application of ratios between BTEX in two Canadian cities, The Scientific World Journal, 11, 2536-2549, doi:10.1100/2011/167973, 2011.

Miller, L., Xu, X., Grgicak-Mannion, A., Brook, J., and Wheeler, A.: Multi-season, multi-year concentrations and correlations amongst the BTEX group of VOCs in an urbanized industrial city, Atmos. Environ., 61, 305-315, doi:10.1016/j.atmosenv.2012.07.041, 2012.

Monod, A.: Monoaromatic compounds in ambient air of various cities: a focus on correlations between the xylenes and ethylbenzene, Atmos. Environ., 35, 135-149, doi:10.1016/S13522310(00)00274-0, 2001.

Nara, H., Nakagawa, F., and Yoshida, N.: Development of twodimensional gas chromatography/isotope ratio mass spectrometry for the stable carbon isotopic analysis of $\mathrm{C}(2)-\mathrm{C}(5)$ nonmethane hydrocarbons emitted from biomass burning, Rapid Commun. Mass. Sp., 20, 241-247, doi:10.1002/rcm.2302, 2006.

National Air Pollution Surveillance Program, Environment and Climate Change Canada, Air monitoring data, available at: http: //www.ec.gc.ca/rnspa-naps/, last access: 22 May 2016.

National Pollutant Release Inventory: Environment and Climate Change Canada, Pollutant Data and Reports, available at: http://www.ec.gc.ca/inrp-npri/default.asp?lang=En\&n= B85A1846-1, last access: 22 May 2016.

Nelson, P. F. and Quigley, S. M.: The m,p-xylenes:ethylbenzene ratio. A technique for estimating hydrocarbon age in ambient atmospheres, Atmos. Environ., 17, 659-662, doi:10.1016/00046981(83)90141-5, 1983.

Niedojadlo, A., Kurtenbach, R., and Wiesen, P.: How reliable are emission inventories? field observations versus emission predictions for NMVOCs, in: Simulation and Assessment of Chemical Processes in a Multiphase Environment, NATO Science for Peace and Security, Series C: Environmental Security, edited by: Barnes, I. and Kharyatonov, M. M., Springer, the Netherlands, 2008.

Pankow, J. F., Luo, W., Bender, D. A., Isabelle, L. M., Hollingsworth, J. S., Chen, C., Asher, W. E., and Zogorski, J. S.: Concentrations and co-occurrence correlations of 88 volatile organic compounds (VOCs) in the ambient air of 13 semi-rural to urban locations in the United States, Atmos. Environ., 37, 50235046, doi:10.1016/j.atmosenv.2003.08.006, 2003.

Parrish, D. D., Hahn, C. J., Williams, E. J., Norton, R. B., Fehsenfeld, F. C., Singh, H. B., Shetter, J. D., Gandrud, B. W., and Ridley, B. A.: Indications of photochemical histories of pacific air masses from measurements of atmospheric trace species at point arena, California, J. Geophys. Res., 97, 15883-815901, doi:10.1029/92JD01242, 1992.

Piccot, S. D., Watson, J. J., and Jones, J. W.: A Global Inventory of Volatile Organic Compound Emissions From Anthropogenic Sources, J. Geophys. Res., 97, 9897-9912, doi:10.1029/92JD00682, 1992.

Rad, H. D., Babaei, A. A., Goudarzi, G., Angali, K. A., Ramezani, Z., and Mohammadi, M. M.: Levels and sources of BTEX in ambient air of Ahvaz metropolitan, Air Qual. Atmos. Health, 7, 515-524, 10.1007/s11869-014-0254-y, 2014.

Redeker, K. R., Davis, S., and Kalin, R. M.: Isotope values of atmospheric halocarbons and hydrocarbons from Irish urban, rural, and marine locations, J. Geophys. Res., 112, D16307, doi:10.1029/2006JD007784, 2007.

Reimann, S. and Lewis, A.: Anthropogenic VOCs, in: Volatile Organic Compounds in the Atmosphere, edited by: Koppmann, R., Blackwell Publishing Ltd, Oxford, 2007.

Richet, P., Bottinga, Y., and Janoy, M.: A review of hydrogen, carbon, nitrogen, oxygen, sulphur, and chlorine stable isotope enrichment among gaseous molecules, Annu. Rev. Earth Pl. Sci., 5, 65-110, doi:10.1146/annurev.ea.05.050177.000433, 1977.

Riemer, D., Pos, W., Milne, P., Farmer, C., Zika, R., Apel, E., Olszyna, K., Klindienst, T., Lonneman, W., Bertman, S., Shepson, P., and Starn, T.: Observations of nonmethane hydrocarbons and oxygenated volatile organic compounds at a rural site in the southeastern United States, J. Geophys. Res., 103, 28111128128., doi:10.1029/98JD02677, 1998.

Roberts, J. M., Fehsenfeld, F. C., Liu, S. C., Bollinger, M. J., Hahn, C., Albritton, D. L., and Sievers, R. E.: Measurements of aromatic hydrocarbon ratios and $\mathrm{NO}_{x}$ concentrations in the rural troposphere: Observation of air mass photochemical aging and $\mathrm{NO}_{x}$ removal, Atmos. Environ., 18, 2421-2432, doi:10.1016/0004-6981(84)90012-X, 1984.

Rudolph, J.: Gas chromatography-isotope ratio mass spectrometry, in: Volatile Organic Compounds in the Atmosphere, edited by: Koppmann, R., Blackwell Publishing Ltd, Oxford, 2007.

Rudolph, J. and Czuba, E.: On the use of isotopic composition measurements of volatile organic compounds to determine the "photochemical age" of an air mass, Geophys. Res. Lett., 27, 38653868, doi:10.1029/2000GL011385, 2000.

Rudolph, J. and Johnen, F. J.: Measurements of light atmospheric hydrocarbons over the Atlantic in regions of low biological activity, J. Geophys. Res., 95, 20583-520591, doi:10.1029/JD095iD12p20583, 1990.

Rudolph, J., Lowe, D. C., Martin, R. J., and Clarkson, T. S.: A novel method for the compound specific determination of $\mathrm{d} 13 \mathrm{C}$ in volatile organic compounds at ppt levels in ambient air, Geophys. Res. Lett., 24, 659-662, doi:10.1029/97GL00537, 1997.

Rudolph, J., Czuba, E., Norman, A. L., Huang, L., and Ernst, D.: Stable carbon isotope composition of nonmethane hydrocarbons in emissions from transportation related sources and atmospheric observations in an urban atmosphere, Atmos. Environ., 36, 1173 1181, doi:10.1016/S1352-2310(01)00537-4, 2002. 
Rudolph, J., Anderson, R. S., Czapiewski, K. V., Czuba, E., Ernst, D., Gillespie, T., Huang, L., Rigby, C., and Thompson, A. E.: The stable carbon isotope ratio of biogenic emissions of isoprene and the potential use of stable isotope ratio measurements to study photochemical processing of isoprene in the atmosphere, J. Atmos. Chem., 44, 39-55, doi:10.1023/A:1022116304550, 2003.

Saccon, M., Kornilova, A., Huang, L., Moukhtar, S., and Rudolph, J.: Stable carbon isotope ratios of ambient secondary organic aerosols in Toronto, Atmos. Chem. Phys., 15, 10825-10838, doi:10.5194/acp-15-10825-2015, 2015.

Saito, T., Tsunogai, U., Kawamura, K., Nakatsuka, T., and Yoshida, N.: Stable carbon isotopic compositions of light hydrocarbons over the western North Pacific and implication for their photochemical ages, J. Geophys. Res., 107, 4040, doi:10.1029/2000JD000127, 2002.

Sawyer, R. F., Harley, R. A., Cadle, S. H., Norbeck, J. M., Slott, R., and Bravo, H. A.: Mobile sources critical review: 1998 NARSTO assessment, Atmos. Environ, 34, 2161-2181, doi:10.1016/S1352-2310(99)00463-X, 2000.

Smallwood, B. J., Philp, R. P., and Allen, J. D.: Stable carbon isotopic composition of gasolines determined by isotope ration monitoring gas chromatography mass spectrometry, Org. Geochem., 33, 149-159, doi:10.106/S0146-6380(01)00142-5, 2002.

Spivakovsky, C. M., Logan, J. A., Montzka, S. A., Balkanski, Y. J., Foreman-Fowler, M., Jones, D. B. A., Horowitz, L. W., Fusco, A. C., Brenninkmeijer, C. A. M., Prather, M. J., Wofsy, S. C., and McElroy, M. B.: Three-dimensional climatological distribution of tropospheric $\mathrm{OH}$ : Update and evaluation, J. Geophys. Res.Atmos., 105, 8931-8980, doi:10.1029/1999JD901006, 2000.

Stein, O. and Rudolph, J.: Modelling and interpretation of stable carbon isotope ratios of ethane in global chemical transport models, J. Geophys. Res., 112, D14308, doi:10.1029/2006JD008062, 2007.
Stevens, C. M., Krout, L., Walling, D., Venters, A., Engelkemeir, A., and Ross, L. E.: The isotopic composition of atmospheric carbon monoxide, Earth Planet. Sci. Lett., 16, 147-165, doi:10.1016/0012-821x(72)90183-5, 1972.

Thompson, A., Rudolph, J., Rohrer, F., and Stein, O.: Concentration and stable carbon isotopic composition of ethane and benzene using a global three-dimensional isotope inclusive chemical tracer model, J. Geophys. Res.-Atmos., 108, D13, doi:10.1029/2002JD002883, 2003.

Turner, N., Jones, M., Grice, K., Dawson, D., Ioppolo-Armanios, M., and Fisher, S.: $\delta^{13} \mathrm{C}$ of volatile organic compounds (VOCS) in airborne samples by thermal desorption-gas chromatographyisotope ratio-mass specrometry (TD-GC-IR-MS), Atmos. Environ., 40, 3381-3388, doi:10.1016/j.atmosenv.2006.01.030, 2006.

United States Environmental Protection Agency, Speciate Data Browser, available at: https://cfpub.epa.gov/si/speciate/ehpa_ speciate_browse_source.cfm?pType $=\mathrm{G} \&$ strBrowseFilter $=\mathrm{G}$, last access: 26 February 2016.

Vitzthum-von Eckstaedt, C, Grice, K., Ioppolo-Armanios, M., Kelly, D., and Gibberd, M.: Compound specific carbon and hydrogen stable isotope analyses of volatile organic compounds in various emissions of combustion processes, Chemosphere, 89, 1407-1413, doi:10.1016/j.chemosphere.2012.06.005, 2012.

Watson, J. J., Ann, P. J., and Piccot, D.: Global inventory of volatile organic compound emissions from anthropogenic sources, United State Environmental Protection Agency, Springfield, VA, 1991.

Wintel, J., Hösen, E., Koppmann, R., Krebsbach, M., Hofzumahaus, A., and Rohrer, F.: Stable carbon isotope ratios of toluene in the boundary layer and the lower free troposphere, Atmos. Chem. Phys., 13, 11059-11071, doi:10.5194/acp-13-11059-2013, 2013. 